NASA Technical Memorandum 100444

\title{
Techniques Used in the F-14 Variable-Sweep Transition Flight Experiment
}

Bianca Trujillo Anderson, Robert R. Meyer, Jr., and Harry R. Chiles

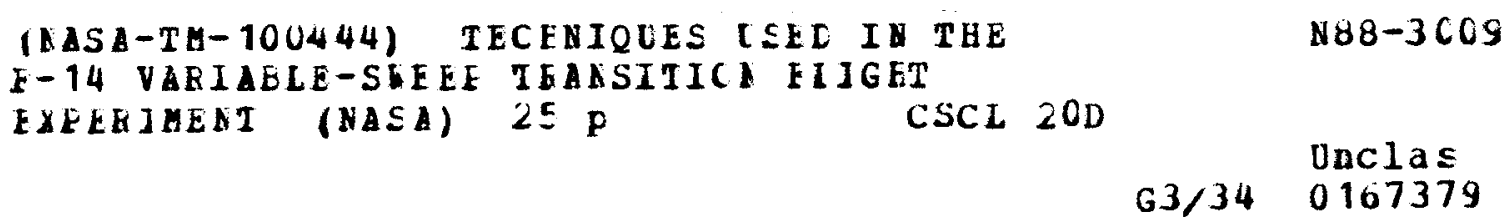

July 1988

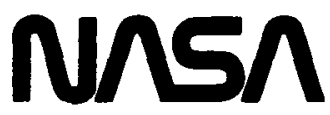

National Aeronautics and

Space Administration 
NASA Technical Memorandum 100444

\section{Techniques Used in the F-14 Variable-Sweep Transition Flight Experiment}

Bianca Trujillo Anderson, Robert R. Meyer, Jr., and Harry R. Chiles

Ames Research Center, Dryden Flight Research Facility, Edwards, California

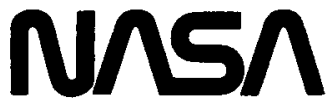

National Aeronautics and

Space Administration

Ames Research Center

Dryden Flight Research Facility

Edwards, California 93523-5000 


\title{
TECHNIQUES USED IN THE F-14 VARIABLE-SWEEP TRANSITION FLIGHT EXPERIMENT
}

\author{
Bianca Trujillo Anderson, ${ }^{*}$ Robert R. Meyer, Jr., ${ }^{*}$ and Harry R. Chiles, ${ }^{\dagger}$ \\ NASA Ames Research Center \\ Dryden Flight Research Facility \\ Edwards, California
}

\begin{abstract}
This paper discusses and evaluates the test measurement techniques used to determine the laminarto-turbulent boundary-layer transition location in the F-14 variable-sweep transition flight experiment (VSTFE). The main objective of the VSTFE was to determine the effects of wing sweep on the laminarto-turbulent transition location at conditions representative of transport aircraft. Four methods were used to determine the transition location: (1) a hot-film anemometer system, (2) two boundary-layer rakes, (3) surface pitot tubes, and (4) liquid crystals for flow visualization. Of the four methods, the hot-film anemometer system was the most reliable indicator of transition.
\end{abstract}

\section{Nomenclature}

AC alternating current, dynamic output signal

B.L. butt line

c chord, in.

$\mathrm{Cp} \quad$ glove coefficient of pressure, $(\mathrm{Ps}-\mathrm{Ps} \infty) / \bar{q}$

DC direct current, steady-state output signal

Ps local static pressure, $\mathrm{lb} / \mathrm{ft}^{2}$

Ps $\infty \quad$ free-stream static pressure, $\mathrm{lb} / \mathrm{ft}^{2}$

Ptl local total pressure measured from surface pitot tubes, $\mathrm{lb} / \mathrm{ft}^{2}$

Ptot aircraft total pressure measured from noseboom, $\mathrm{lb} / \mathrm{ft}^{2}$

$\Delta \mathrm{P} \quad$ difference between aircraft total pressure and local total pressure, measured from the surface pitot tubes, (Ptot - Ptl), lb/ft ${ }^{2}$

$\bar{q} \quad$ dynamic pressure, $\mathrm{lb} / \mathrm{ft}^{2}$

U/Umax ratio of local velocity to freestream velocity

*Aerospace Engineer, member AIAA.

${ }^{\dagger}$ Aerospace Engineer.

\author{
VSTFE variable-sweep transition flight \\ experiment \\ $\mathrm{x} / \mathrm{c} \quad$ ratio of chordwise distance from leading \\ edge to local chord length \\ $\mathrm{Y}$ distance from glove surface, in. \\ $\alpha \quad$ angle of attack, deg \\ $\delta \quad$ boundary-layer height, in. \\ $\delta * \quad$ displacement thickness, in., \\ $\int(1-\mathrm{U} / \mathrm{U} \max ) d \mathrm{Y}$ \\ $\Theta \quad$ momentum thickness, in., \\ $\frac{\int\left(1+0.2 \mathrm{M}^{2}\right) \mathrm{U}}{\left(1+0.2 \mathrm{M}^{2} \infty\right) \mathrm{U} \max }(1-\mathrm{U} / \mathrm{U} \max ) d \mathrm{Y}$
}

\section{Introduction}

As is well known, maintaining laminar flow over large regions of an aircraft's wing and empanage can produce large reductions in airplane drag. Laminar flow can be achieved either through passive or active means. By properly shaping the wing to obtain a pressure distribution with a favorable gradient, laminar flow can be achieved in a passive manner but is limited to relatively low-chord Reynolds numbers and small sweep angles. Although more complicated, active laminar flow or laminar flow control uses suction through the wing surface to maintain laminar flow up to 100 percent chord and to very high chord Reynolds numbers. For laminar flow applications to most highspeed commercial transports, some degree of laminar flow control will probably be necessary.

Several studies have shown laminar flow technology to be extremely beneficial for long-range transport aircraft; ${ }^{1-6}$ however, significantly more technology validation needs to be carried out before laminar flow technology can be confidently applied. A better understanding of transition and how to predict it is also needed in order to design laminar flow wings. Larger transports are generally designed to have swept wings ( $20^{\circ}$ or more), chord lengths as long as $20 \mathrm{ft}$, and op- 
erate at unit Reynolds numbers of 1 to $4 \mathrm{million} / \mathrm{ft}$. Therefore, the effects of wing sweep and Reynolds number on boundary-layer transition must be studied further.

Determining the boundary-layer transition location at conditions representative of transport aircraft has been largely limited to flight testing because the Reynolds numbers, model size, and low-turbulence levels needed at transonic speeds prohibit the use of wind tunnels. Accurate predictions of laminar-toturbulent boundary-layer transition are also difficult to obtain because current boundary-layer stability codes are not fully developed and verified.

Recently, an experiment was devised to determine the effects of wing sweep on boundary-layer transition location at flight conditions representative of transport aircraft. Performed on the swing-wing F-14 aircraft, the experiment, referred to as the F-14 variable sweep transition experiment (VSTFE), ${ }^{7-10}$ was a joint effort between NASA Langley Research Center and NASA Ames-Dryden Flight Research Facility. The experiment involved using a foam and fiberglass technique to fit a smooth, contoured surface to the wing of the aircraft. Two of these devices, called natural laminar flow wing gloves, were flight tested. Glove 1 was flown in the first and second phases of the experiment, and glove 2, only in the second phase of the experiment. Four different techniques were used to accurately determine the boundary-layer transition location on the gloves:

(1) hot-film anemometer system

(2) boundary-layer rakes

(3) surface pitot tubes

(4) flow visualization using liquid crystals

This paper discusses the results of these four measurement techniques.

\section{Test Aircraft}

The F-14A aircraft (Fig. 1) was the carrier vehicle for the experiment. The F-14A has variable-wingsweep capability and its flight envelope includes the Mach and Reynolds number range suitable for testing at conditions representative of modern intermediatesize transport aircraft.

Both wing panels were modified by bonding an upper-surface glove constructed of foam and fiberglass using the techniques described in Ref. 11. Each glove wrapped around the leading edge and extended back to the spoiler hinge line on the upper surface $(\approx 60$ percent chord, Fig. 2) and covered the majority of the span. These gloves provided a smooth surface (that is, $<0.002$ in. amplitude/2 in.) as well as space to install instrumentation, plumbing, and wiring.

Glove 1 , a cleanup of the basic F-14A wing was installed on the left wing panel. The basic F-14 airfoil shape (a modified NASA 6 series) was used because it could provide pressure distributions with very favorable pressure gradients near Mach 0.8. Glove 2, installed on the right wing panel, involved major modifications to the F-14 airfoil shape, but it provided a much broader Mach number range and a variety of pressure distributions, for which transition data could be obtained. With glove 2, wind tunnel tests were required to verify that the aircraft handling qualities had not been degraded. With the gloves installed, the maximum wing sweep was restricted to $35^{\circ}$.

\section{Instrumentation}

The F-14A aircraft was instrumented with a standard NACA noseboom ${ }^{12-13}$ to measure total and static pressure, angle of attack, and angle of sideslip. The cockpit was instrumented with an uplink display system described in Ref. 14. The uplink was used to assist the pilot in obtaining accurate flight conditions for each test point in a timely manner. All instrumentation used in the VSTFE was selected and scaled to suit each parameter being measured.

The transition instrumentation for glove 1 (Fig. 3) consisted of three rows of 21 flush static pressure orifices, two boundary-layer rakes with 20 probes each, three rows of 11 surface pitot tubes, and five hot-film sensors. The transition instrumentation for glove 2 (Fig. 4) consisted of four rows of 24 flush static pressure orifices, two boundary-layer rakes with 20 probes each, and 15 hot-film sensors. The two sets of instrumentation are different for two reasons: One, the instrumentation system used for glove 2 was selected based on the results of the instrumentation system used for glove 1, which was flown first. Two, during the glove 1 flight tests, further developments were being made in the measurement systems, and these developments were incorporated into the glove 2 instrumentation systems.

\section{Surface Static Pressure Orifices}

The surface static pressures were used to examine the wing pressure distribution and to determine the 
amount of favorable pressure gradient obtained for each test point. Flush-surface orifices were created by drilling through the foam and fiberglass to a 1-in.diameter hollow metal disk buried in the glove. Each orifice had an inside diameter of $0.03 \mathrm{in}$. The individual disks were connected to an electronic scanning pressure module with steel tubing. The maximum tube length was approximately $10 \mathrm{ft}$. Each orifice row was oriented streamwise to the flow for a wing sweep of $20^{\circ}$. The orifice locations for the orifice rows of gloves 1 and 2 are presented in table 1.

\section{Boundary-Layer Rakes}

Each boundary-layer rake consisted of 20 pressure probes. These rake probes were mounted along a 4in. plate that was skewed $30^{\circ}$ to a plane normal to the glove surface, as shown in Fig. 5. Skewing the rake plate allowed more probes to be located in the boundary layer. With this type of orientation, the last probe on the rake was 2.5 in. from the glove surface. Each rake was oriented streamwise to the flow for a wing sweep of $20^{\circ}$. The pressure at each probe was measured by an electronic scanning pressure module connected to the probes by steel tubing. The distance of each probe from the glove surface is shown in table 2 .

\section{Surface Pitot Tubes}

The surface pitot tubes had an inside diameter of 0.032 in. (Fig. 6) and were mounted flush to the glove surface. For the first half of the glove 1 flights, the tubes were left rounded. For the second half of the flights, the tubes were flattened into an oval shape with a height of $0.010 \mathrm{in}$.

Three rows of surface pitot tubes were mounted on glove 1 , with a maximum of eleven tubes/row. As illustrated in Fig. 3, each row was located along a line oriented at a $30^{\circ}$ angle to each orifice row. The purpose for this orientation was to alleviate interferences between each tube and the hot films, which were also oriented along this line. Each individual tube, however, was oriented to be streamwise to the flow for a wing sweep of $20^{\circ}$. The pressure measurements from each surface pitot tube was made by extending a tube to a maximum of $10 \mathrm{ft}$ from the surface pitot tube to a 32-port, electronic scanning pressure module. The surface pitot tubes were not installed on glove 2.

\section{Hot-Film Sensors}

Five hot-film sensors were operational for glove 1 and fifteen were for glove 2. The location of the operational hot-film sensors for both gloves varied from flight to flight. The glove 1 hot-film system used constant-temperature hot-film anemometers because many years of wind tunnel and some recent flight experience ${ }^{5,15-17}$ had demonstrated the ability of the anemometers to provide reliable flow transition data. Based on the results from the glove 1 flights and the desire for more measurements to reduce the number of flights for acquiring data, a newly designed temperature-compensated hot-film anemometer system was used for glove 2. Each system is briefly described next.

The hot-film sensors, as shown in Figs. 3 and 4, were mounted along a line oriented at a $30^{\circ}$ angle to the leading edge of the glove to minimize any flow disturbance from one sensor affecting another sensor (flow is turbulent after each sensor). The typical hot-film-sensor spacing was 10, 20, 30, 40 and 50 percent chord; however some data were obtained with the hot-film sensors spaced every 5 percent chord. The hot-film sensors for glove 1 (Fig. 7a) were oriented streamwise to the flow for a wing sweep angle of $20^{\circ}$. Because the hot-film sensors used for the glove 2 system (Fig. 7b) were expected to be more sensitive to flow angle, the hot-film sensor orientation was tilted $5^{\circ}$, making them streamwise to the flow at a wing sweep of $25^{\circ}$. Both types of hot films were able to detect transition to the maximum sweep angle of $35^{\circ}$.

All of the operational hot-film sensors of gloves 1 and 2 were monitored real-time through stripchart recorder traces. For postflight analysis, five of the hot-film output signals were recorded on an airborne FM tape recorder for the glove 1 flights, and eight of the hot-film signals (three from glove 1 and five from glove 2) were recorded on the tape for the glove 2 flights. The recorded hot-film signals were also monitored in the F-14 cockpit by means of a cockpit audio system.

In addition to the normal $\mathrm{AC}$ dynamic output, the temperature-compensated hot-film anemometer used on glove 2 also provided a DC steady-state output for telemetry. Internal signal conditioning for both the dynamic and steady-state outputs is contained within the temperature-compensated hot-film anemometer. The frequency response of the hot-film sensors was $150 \mathrm{kHz}$, as determined by the manufacturer. The tape recorder used, however, had a frequency response of $10 \mathrm{kHz}$ thereby limiting the recorded hot-film data to a frequency response of $10 \mathrm{kHz}$. 
Functional block diagrams of the hot-film systems are shown in Fig. 8. In both hot-film systems the amplifier that provided the output signal also supplied power to the hot-film sensor causing self heating of the sensor to the operating temperature. The hotfilm-sensor operating temperature was set by the temperature control resistor for the constant-temperature anemometer system used on glove 1 and was constant for all flight conditions. The temperature-compensated hot-film anemometer system used on glove 2 used a temperature sensor and compensation network that allowed the operating temperature to vary with the local stagnation temperature. Because changes in the boundary-layer flow vary the cooling effect on the heated active element of the hot-film sensor, the output of the anemometer varies, thus providing an indication of the flow condition.

The glove 2 hot-film anemometer has a much lower power dissipation than that of the glove 1 anemometer because the hot-film-sensor operating temperature is reduced as the sensed temperature decreases. The lower power dissipation reduces the heating of the anemometer electronics that allows a greater miniaturization. The fifteen temperature-compensated hot-film anemometers for glove 2 required slightly less space than the five constant-temperature hot-film anemometers for glove 1 .

The design of the temperature-compensated hotfilm anemometer for glove 2 allows noise induced in the sensors and wiring to be rejected by the hot-film anemometer electronics. The noise rejection of the anemometer allows the use of two-conductor shielded wire, instead of coaxial wiring for the hot-film sensor and temperature sensor installation. The anemometer provides a significant improvement in output signal to noise (greater than $65 \mathrm{~dB}$ ) over the hot-film anemometer system used for glove 1 .

Other advantages of the temperature-compensated hot-film anemometer is a near-constant sensitivity over the flight envelope of the test aircraft and although not important for this flight project, better operation at supersonic flight. A detailed description of the design and use of the temperature-compensated hot-film anemometer is contained in Ref. 18.

\section{Test Conditions}

Boundary-layer transition data were obtained at the flight conditions listed in table 3. Transition data at $15^{\circ}$ of sweep were obtained by using a sideslip maneuver because the minimum wing sweep available was $20^{\circ}$. The aircraft would fly the test point with $\pm 5^{\circ}$ of sideslip to obtain an equivalent wing sweep of $15^{\circ}$ for the right and left gloves, respectively. For all flights the aircraft slats and flaps were locked in a retracted position and the glove vanes were disabled.

The maneuvers used to obtain data were steadystate trim points, windup turns, or pushovers. Using these three maneuvers, data at angles of attack other than trim were acquired for constant Mach, sweep, and altitude.

\section{Results}

The four techniques used to determine the transition location are discussed in the following sections. The transition data shown represents typical examples of the data obtained. A more detailed analysis of the VSTFE transition data is ongoing and will be reported at a later date.

\section{Hot-Film Data}

The results obtained from the hot-film anemometers were based on AC (dynamic) and DC (steady-state) signals. An example of a typical dynamic signal is shown in Fig. 9a. Dynamic signals originating in areas of laminar flow were of lower amplitude or "quieter" than those originating in areas of turbulent flow. Additional indicators were high amplitude spikes in the output signal; high amplitude spikes in a direction of positive voltage indicated a mostly laminar signal with occasional turbulent bursts, while high amplitude spikes in a negative direction indicated a mostly turbulent signal with occasional laminar bursts. These two types of signals were indicators of the beginning and ending of the transition region. Maximum occurrence of these high amplitude spikes was at peak transition, the region where the flow is most unstable. The transition location was defined as the location where peak transition occurred. In many cases the hot-film sensors were not spaced close enough to always define the transition region. In cases where one sensor was laminar and the next was fully turbulent, transition was defined at the midpoint. The real-time ground station dynamic signal plots were generally acceptable for determining transition location; however in some cases the postflight, high-frequency response plots were needed for clarification.

An example of a typical steady-state signal is shown in Fig. 9b. Steady-state signals originating in areas of laminar flow were of a lower level than those originating in areas of turbulent flow. In general, instantaneous 
changes in the steady-state level indicated peak transition. The instantaneous changes or oscillations in the steady-state signal level occurred because the steadystate signal had a frequency response of $500 \mathrm{~Hz}$. This allowed some of the dynamic signal to be picked up by the steady-state signal. The real-time, ground station steady-state-signal time histories were usually acceptable; however, in areas at or nearing peak transition the postflight dynamic signal plots were sometimes necessary to aid in interpreting the steady-state output data.

Figure 10 presents examples of anomalies encountered in the steady-state signal. A comparison is made between two steady-state and dynamic signals at the same time intervals. The steady-state signal is at a laminar level for each case. The corresponding dynamic signal is laminar for case a and fully turbulent for case b. With these types of discrepancies existing in the steady-state signal in areas at or near the transition location, the dynamic signal was easier to interpret.

The degree to which transition can be determined is limited only by the distance between the hot-film sensors and experience in interpreting the hot-film output signal. For the VSTFE the hot-film spacing wasgenerally 10 percent chord (c) for glove 1 and most of glove 2 data, however some glove 2 data were obtained with a hot-film sensor spacing of 5 percent $c$ for better resolution.

As shown in Fig. 9a, the dynamic signal indicated whether a hot film was in laminar flow, laminar flow with turbulent bursts, peak transition, turbulent flow with laminar bursts, or fully turbulent flow. Based on these five types of signals, if two hot films were spaced 10 percent $c$ apart (that is, 10 and 20 percent $c$ ), one could determine if the transition location was between the two gauges ( 15 percent $c$ ), closer to the first gauge (12.5 percent $\mathrm{c}$ ), closer to the second gauge (17.5 percent $c$ ), or right on the sensor itself ( 10 or 20 percent $c)$.

On glove 2 several flights of data were obtained with the hot films spaced at both 10 percent $c$ and 5 percent $c$. Figure 11 shows the transition location plotted as a function of angle of attack for hot-film spacings of 5 and 10 percent at a typical flight condition. This figure indicates that there was very little scatter in the two sets of data. The majority of differences found were no greater than 2.5 percent c. The relatively low amount of scatter in the data, between the 10 percent and 5 percent chord spacing, is attributed to the ability to interpret the dynamic signal output previously described. Based on the spacing of the hot- film sensors, the five types of dynamic hot-film outputs, and the experience gained in interpreting data for 2700 test points, the accuracy of the transition data obtained from the hot-films is estimated at \pm 2.5 percent $c$ for gloves 1 and 2. The transition data obtained did not define the entire transition region (that is, the first occurrence of a turbulent burst to the last occurrence of a laminar burst). Defining the transition region would require closer spacing of the hot-film sensors.

\section{Boundary-Layer Data}

The boundary-layer rake data provided a velocity profile of the boundary-layer and skin-friction-related parameters such as boundary-layer height, $\delta$, displacement thickness, $\delta *$, and momentum thickness, $\Theta .{ }^{19} \mathrm{~A}$ typical boundary-layer profile with the corresponding calculated values of $\delta, \delta *$, and $\Theta$ is shown in Fig. 12 . The skin friction parameters were available only from the boundary-layer rake data.

Determining the transition location from the boundary-layer rake data required a calibration of the boundary-layer thickness as a function of chordwise transition location. Calibration of the rake data was achieved by forcing the boundary layer to transition at various chord locations using a 1/8-in.-wide transition strip of Carborundum grit. The grit was sized using the method described in Ref. 20. When the flow is forced to transition at known locations, $\delta, \delta *$, and $\Theta$ can be obtained as a function of the chordwise transition location and the angle of attack.

When the rake calibration was completed, the location of natural transition for the glove could be determined. An example of a calibration plot with naturally transitioning data is shown in Fig. 13. Figure 13 is a plot of momentum thickness as a function of angle of attack for data obtained at the same flight condition as the data shown in Fig. 12. Each line indicates values of $\Theta$ obtained when the boundary layer was forced to transition using the transition strips at the indicated chordwise locations, 10,30 and 40 percent $c$. The $\Theta$ value for the velocity profile in Fig. 12 is plotted in Fig. 13, along with the rest of the natural transitioning data at the same flight condition, and is represented by a solid circle. Based on Fig. 13, natural transition occurs aft of 40 percent $c$ and begins to move forward as the angle of attack increases.

A comparison of the transition results from the boundary-layer rake data and the hot-film data is presented in Fig. 14. The boundary-layer rake data agreed to within \pm 5 percent $c$ with the hot-film data. For the 
have picked up local adverse changes in total pressure, that did not in all cases cause transition and may not have occurred uniformly across the span of the glove. These adverse changes in pressure may not have been detected by the hot films because the two sets of instrumentation were not at the same $x / c$ or span locations. Laminar flow is capable of withstanding a small level of adverse pressure gradient in some cases and, therefore, a small level of increased local total pressure may not always be the result of laminar-toturbulent transition.

Because of the many anomalies, the criteria used to determine transition from the surface pitot tube data was not always successful. Although the surface pitot method used in this experiment was not entirely successful, previous experiments have used surface pitot tubes successfully to indicate transition. Past experiments, ${ }^{21-23}$ however, have used a higher probe density or a traversing probe, producing higher resolution data. More surface pitot tubes would have increased the resolution of the $\Delta P$ as a function of $x / c$ curves. However, with the glove 1 instrumentation configuration, adding more surface pitot tubes was not feasible.

\section{Flow Visualization Data}

The fourth method used to determine the transition location was flow visualization using pressuresensitive liquid crystals. This technique is similar to that used in Ref. 24. The middle test section of glove 1 and all of glove 2 were painted black to provide contrast for the liquid crystals. The liquid crystal mixture was applied to the glove surface before takeoff.

By using a chase plane, both still and video photography of the the liquid crystal patterns were obtained. For both types of documentation the photographer was in a chase plane, positioned at the proper viewing angle for each test point. Figure 22 shows examples of liquid crystal patterns. Transition is indicated by a change in color in the liquid crystal pattem. The colors themselves are not important because they change with viewing angle as well as with the transition location.

Figure 23 presents a comparison of liquid crystal and hot-film transition data obtained at the same time intervals. Data is included for glove 1 and glove 2. This figure shows that the transition location indicated by the liquid crystal pattern agreed to within \pm 5 percent $c$ with the hot-film indication of transition location at the same time interval. If a hot film was behind a turbulent wedge, the hot-film sensor would in- dicate turbulent flow or flunctuation between laminar and turbulent flow. Based on the good agreement between the liquid crystal patterns and the hot-film data for the same time interval, the hot-film sensors were used to indicate transition locations with liquid crystals on the surface for test points where photographs were not taken.

Figure 24 shows a comparison of transition data obtained with and without liquid crystals on the glove surface. The transition location is plotted as a function of angle of attack. At the lower altitude a variation in the transition location of up to 30 percent $c$ is evident between the two sets of data. All of the transition data obtained with liquid crystals on the glove surface fall below the transition data obtained without the liquid crystals on the glove surface.

In the high-altitude plot of figure 24 there is only a 5 percent $c$ variation in the transition location for all of the data obtained. The transition data with the liquid crystals on the glove surface is at the maximum transition location. The variation in the high-altitude data exists only in the data obtained without liquid crystals on the glove surface and does not exist in the liquid crystal data. Therefore, the variation is not because of the presence of the liquid crystals.

The use of liquid crystals for flow visualization produced mixed results. The advantage of the liquid crystal patterns is that transition is obtained globally as opposed to several discrete locations. The flow visualization method is relatively easy to use and requires only a camera for documentation.

Several drawbacks were noted, however. The first is that insects and dust tend to adhere to the glove surface in greater amounts with the presence of the liquid crystals. The insect impacts and dust particles produce discontinuities that can cause localized transition. The flow is turbulent in the region behind the discontinuity. The localized turbulent region appears as a wedge in the liquid crystal pattern such as those found in Fig. 22(a).

Second, an uneven thickness in the liquid crystal coat can cause changes of the color in the liquid crystal pattern, interfering with the interpretation of the pattern. Therefore, care must be taken in applying the liquid crystal coat evenly. Third, at lower altitudes (that is, $<25,000 \mathrm{ft}$ )/higher unit Reynolds numbers, the presence of the liquid crystals was observed to move the transition location forward, as illustrated in Fig. 24. 
Comparing the four techniques, the hot-film data was the easiest to interpret. Transition was indicated in real time by the hot films, whereas the data obtained from all the other methods had to be analyzed postflight. In addition, the boundary-layer data needed to be calibrated, which required several flights. The boundary-layer rakes produced repeatable data, however, and were used as a secondary method. The surface pitot tube data did not consistently indicate transition, although they have been successfully used in previous experiments. The liquid crystals were the easiest to use. At altitudes above $25,000 \mathrm{ft}$, the transition location indicated by the liquid crystal patterns agreed with the hot-film and boundary-layer data. However, the liquid crystals caused transition to occur further forward at altitudes below $25,000 \mathrm{ft}$.

\section{Conclusions}

Presented in this paper were the results of using four techniques to determine the laminar-to-turbulent boundary-layer transition location in the variablesweep transition flight experiment (VSTFE). The four techniques were (1) a hot-film anemometer system, (2) boundary-layer rakes, (3) surface pitot tubes, and (4) liquid crystals for flow visualization.

The hot-film anemometer system provided the most accurate indication of the transition location and was the primary method used in the VSTFE to determine the transition location. Transition was determined from both dynamic and steady-state hot-film signals in real time. Of the two types of hot-film output signals, the dynamic signal was a better indicator of the transition location when the transition occurred at or near the hot-film sensor. The accuracy of the data obtained with the hot-film anemometer system used in the VSTFE was approximately \pm 2.5 percent $c$. Closer spacing of the hot films would be required, however, to define the entire transition region.

The boundary-layer rakes served as a good secondary indicator of the transition location. The boundary-layer-rake data agreed to within \pm 5 percent c with the hot-film data. At several test conditions a shock would occur ahead of the rakes, resulting in boundary-layer profiles with severe inflections. For these cases the boundary-layer-rake data was not used to determine the transition location. One advantage of the boundary-layer-rake method is that it provided skin-friction-related parameters in addition to an indication of the transition location.

The surface pitot tube method used in the VSTFE did not consistently indicate transition. There were many cases where more than one apparent transition location was indicated by the surface pitot tube data. The first transition location indicated by the surface pitot tube data generally agreed with the hot-film data for the lower altitude cases, while the second transition location indicated by the surface pitot tube data agreed with the hot-film data for the higher altitude cases. Some of the decreases in $\Delta \mathrm{P}$ did correspond to sudden changes in the pressure distributions; however, not all of the anomalies can be accounted for. One improvement in the surface pitot tube configuration would have been closer spacing of the surface pitot tubes. Unfortunately this was not a feasible alternative for the VSTFE.

The liquid crystals were very useful as a tool for flow visualization. It provides a global view of the transition location. The liquid crystal method is easiest to use because no instrumentation is required, only a camera. However, there were certain drawbacks. With the presence of the liquid crystals on the glove surface, an increase in the amount of insect impacts was noted. Color changes occurred in the liquid crystal patterns as a result of uneven thicknesses in the liquid crystal coats. Last, the transition location had a tendency to move forward at lower altitudes or higher unit Reynolds numbers with the presence of the liquid crystals on the glove surface.

Overall the test techniques used were successful in indicating the transition location and can be useful for boundary-layer and fluid dynamics-related experiments.

\section{References}

${ }^{1}$ Montoya, Lawrence C.; Steers, Louis L.; Christopher, David; and Trujillo, Bianca: F-111 TACT Natural Laminar Flow Glove Flight Results. NASA CP$2208,1981$.

${ }^{2}$ Meyer, Robert R. Jr. and Jennett, Lisa A.: InFlight Surface Oil-Flow Photographs With Comparisons to Pressure Distribution and Boundary-Layer Data. NASA TP-2395, 1985. 
${ }^{3}$ Boeing Commercial Airplane Company: Natural Laminar Flow Airfoil Analysis and Trade Studies. NASA CR-159029, 1979.

${ }^{4}$ Wagner, R.D.; and Fischer, M.C.: Developments in the NASA Transport Aircraft Laminar Flow Program. AIAA-83-0090, Jan. 1983.

${ }^{5}$ Runyan, L.J.; Bielak, G.W.; Behbehani, R.; Chen, A.W.; and Rozendaal, R.A.: 757 NLF Glove Flight Test Results. Natural Laminar Flow and Laminar-Flow Control, NASA CP-2487, Part 3, 1987, pp. 795-818.

${ }^{6}$ Rozendaal, R.A.: Natural Laminar Flow Flight Experiments on a Swept Wing Business Jet-Boundary Layer Stability Analyses. NASA CR-3975, 1986.

${ }^{7}$ Meyer, Robert R.; Trujillo, Bianca M.; and Bartlett, Dennis W.: F-14 VSTFE and Results of the Cleanup Flight Test Program. Natural Laminar Flow and Laminar-Flow Control, NASA CP-2487, Part 3, 1987, pp. 819-844.

${ }^{8}$ Waggoner, E.G.; Campbell, R.L.; Phillips, P.S.; and Hallissy, J.B.: Design and Test of an NLF Wing Glove for the Variable-Sweep Transition Flight Experiment. Natural Laminar Flow and Laminar-Flow Control, NASA CP-2487, Part 3, 1987, pp. 753-776.

${ }^{9}$ Rozendaal, R.A.: Variable-Sweep Transition Flight Experiment (VSTFE) - Stability Code Dev'elopment and Clean-Up Glove Data Analysis. Natural Laminar Flow and Laminar-Flow Control, NASA CP2487, Part 3, 1987, pp. 845-859.

${ }^{10}$ Rozendaal, Roger A.: Variable Sweep Transition Flight Experiment(VSTFE)-Parametric Pressure Distribution Boundary Layer Stability Study and Wing Glove Design Task. NASA CR-3992, 1986.

"Bohn-Meyer, Marta: Constructing "Gloved Wings" for Aerodynamic Studies. AIAA-88-2109, May 1988.

${ }^{12}$ Gracy, William; Letko, William; and Russell, Walter R.: Wind-Tunnel Investigation of a Number of Total-Pressure Tubes at High Angles of Attack Subsonic Speeds. NACA TN-2331, 1951.

${ }^{13}$ Sakamoto, Glenn M.: Aerodynamic Characteristics of a Vane Flow Angularity Sensor System Capable of Measuring Flightpath Accelerations for the Mach Number Range From 0.4 To 2.54. NASA TN D-8242, 1976.
${ }^{14}$ Meyer, R.R., Jr.; and Schneider, Cdr. E.T.: RealTime Pilot Guidance System For Improved Flight Test Maneuvers. AIAA-83-2747, Nov. 1983.

${ }^{15}$ Chiles, Harry R. and Johnson, J. Blair.: Development of a Temperature-Compensated Hot-Film Anemometer System for Boundary-Layer Transition Detection on High-Performance Aircraft. NASA TM86732, 1985.

${ }^{16}$ Collier, F.S.; Johnson, J.B.; Rose, O.J.; and Miller, D.S.: Supersonic Boundary-Layer Transition on the LaRC F-106 and the DFRF F-15 Aircraft. Natural Laminar Flow and Laminar-Flow Control, NASA CP-2847, Part 3, 1987, pp. 997-1024.

${ }^{17}$ Johnson, J. Blair.: Preliminary In-Flight Boundary Layer Transition Measurements on a 45-Degree Swept Wing at Mach Numbers Between 0.9 and 1.8. NASA TM-100412, 1988.

${ }^{18}$ Chiles, Harry R.: The Design and Use of a Temperature-Compensated Hot-Film Anemometer System for Boundary-layer Flow Transition Detection on Supersonic Aircraft. NASA TM-100421, 1988.

${ }^{19}$ Saltzman, Edwin J.; and Fisher, David F.: Some Turbulent Boundary-Layer Measurements Obtained From the Forebody of an Airplane at Mach Numbers up to 1.72. NASA TN D-5838, 1970.

${ }^{20}$ Braslow, Albert L.; and Knox, Eugene C.: Simplified Method for Determination of Critical Height of Distributed Roughness Particles for Boundary-Layer Transition at Mach Numbers from 0 to 5. NACA TN4363, 1958.

${ }^{21}$ Fisher, David F.; and Fischer, Michael C.: Development Flight Tests of JetStar LFC Leading-Edge Flight Test Experiment. NASA CP-2487, Part 1, 1987, pp. 117-140.

${ }^{22}$ Fisher, David F.; and Dougherty, N. Sam, Jr.: InFlight Transition Measurement on a $10^{\circ}$ Cone at Mach Numbers From 0.5 to 2.0. NASA TP-1971, 1982.

${ }^{23}$ Matting, Fred W.; Chapman, Dean R.; Nyholm, Jack R.; and Thomas, Andrew G.: Turbulent Skin Friction at High Mach Numbers and Reynolds Numbers in Air and Helium. NASA TR R-82, 1961.

${ }^{24}$ Holmes, Bruce J.; Gall, Peter D.;Croom, Cynthia C.; Manuel, Gregory S.; and Kelliher, Warren C.: A New Method for Laminar Boundary Layer Transition Visualization in Flight-Color Changes in Liquid Crystal Coatings. NASA TM-87666, 1986. 
Table 1 Orifice locations

\begin{tabular}{cccc}
\hline \multicolumn{2}{c}{ Glove 1 } & \multicolumn{3}{c}{ Glove 2} \\
Upper surface $\mathrm{x} / \mathrm{c}$ & Lower surface $\mathrm{x} / \mathrm{c}$ & Upper surface $\mathrm{x} / \mathrm{c}$ & Lower surface $\mathrm{x} / \mathrm{c}$ \\
\hline 0.0 & 0.005 & 0.0 & 0.0015 \\
0.005 & 0.01 & 0.0015 & 0.005 \\
0.01 & & 0.003 & 0.01 \\
0.02 & & 0.005 & \\
0.04 & 0.01 & \\
0.06 & 0.02 & \\
0.08 & 0.04 & \\
0.10 & 0.06 & \\
0.12 & 0.08 & \\
0.15 & 0.10 & \\
0.17 & 0.12 & \\
0.20 & 0.15 & \\
0.25 & 0.17 & \\
0.30 & 0.20 & \\
0.35 & 0.25 & \\
0.40 & 0.30 & \\
0.45 & 0.35 & \\
0.50 & 0.40 & \\
0.55 & 0.45 & \\
& 0.50 & \\
\hline
\end{tabular}


Table 2

Boundary-layer rake probe locations

\begin{tabular}{rr}
\hline Probe & Y, in. \\
\hline 1 & 0.04 \\
2 & 0.06 \\
3 & 0.10 \\
4 & 0.15 \\
5 & 0.20 \\
6 & 0.25 \\
7 & 0.30 \\
8 & 0.35 \\
9 & 0.40 \\
10 & 0.50 \\
11 & 0.70 \\
12 & 0.90 \\
13 & 1.10 \\
14 & 1.30 \\
15 & 1.50 \\
16 & 1.70 \\
17 & 1.90 \\
18 & 2.10 \\
19 & 2.30 \\
20 & 2.50 \\
\hline \hline
\end{tabular}

Table 3 Test conditions

\begin{tabular}{cc}
\hline Sweep, deg & \multicolumn{1}{c}{ Sideslip, deg } \\
\hline 20 & $0,5,-5$ \\
25 & 0 \\
30 & 0 \\
35 & 0 \\
\hline \hline Mach-0.6,0.65, 0.7,0.75, \\
$0.8,0.825$ \\
Altitude-10,000, 20,000, \\
25,000, 30,000, 35,000 ft \\
Angle of attack- $0^{\circ}$ to $5^{\circ}$
\end{tabular}




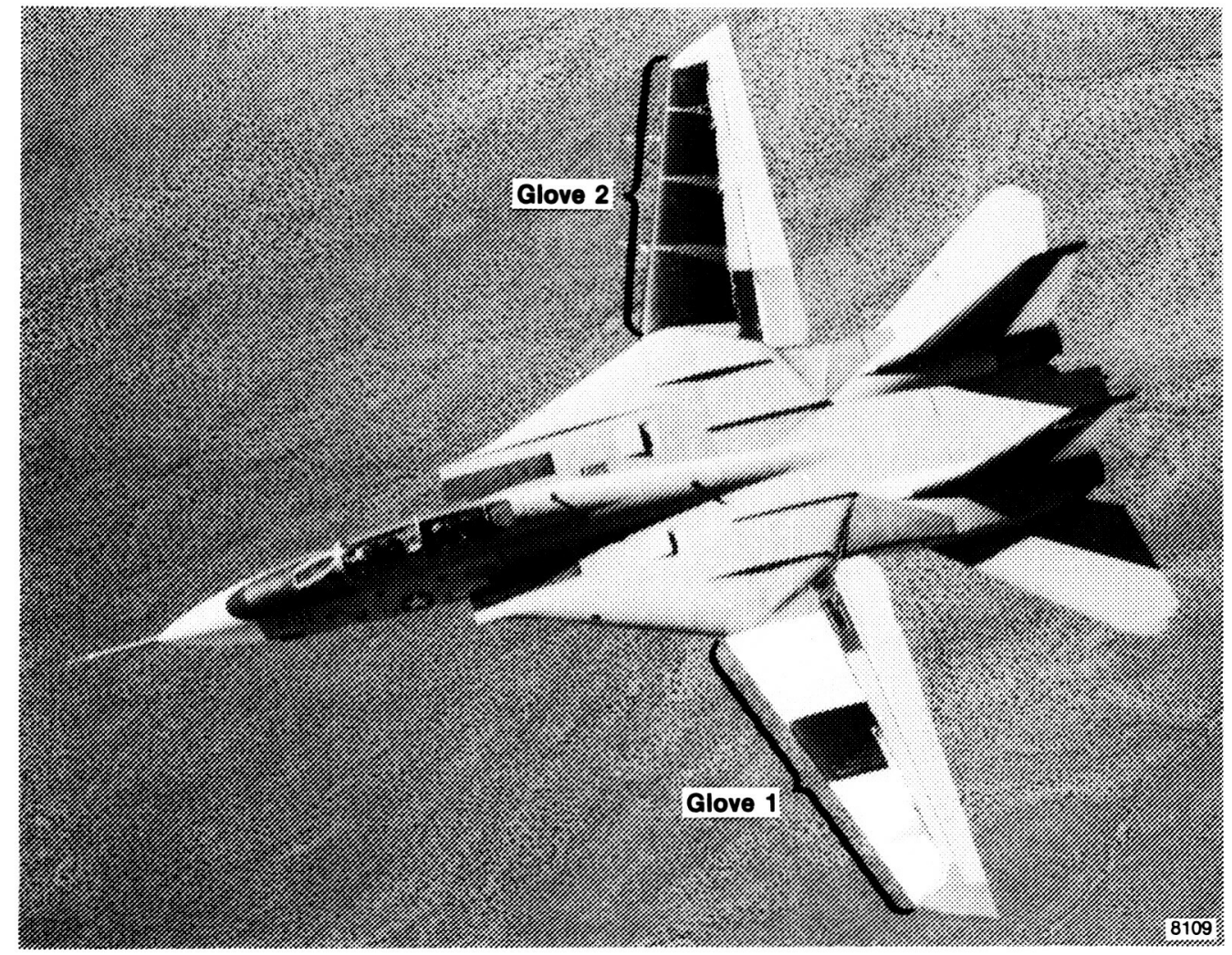

EC 87-0107-001

Fig. 1 F-14A with gloves 1 and 2.

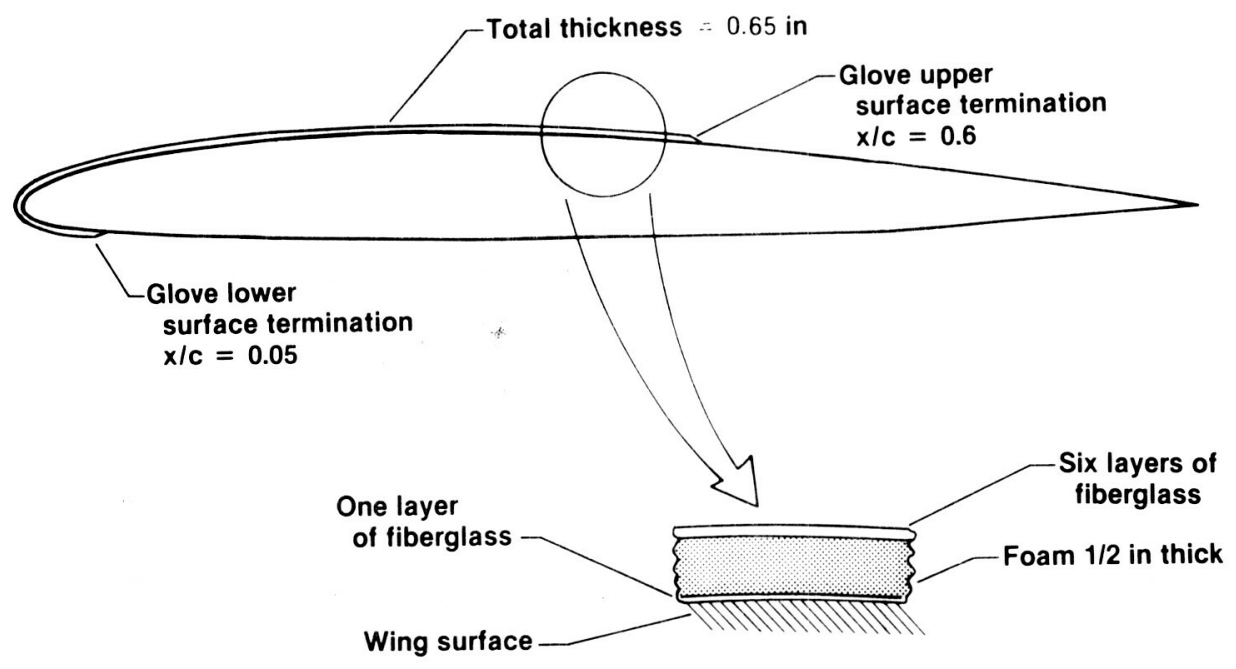

Fig. 2 Fiberglass glove fitted over F-14 wing. 

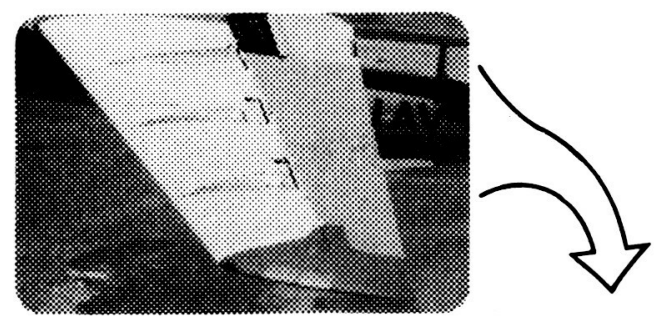

- Three rows of flush static pressure orifices

- Three rows of surface pitot tubes

- Five hot-film gauges

- Two boundary layer rakes

- Uplink

Surface

Pitot tubes I

hot films

B.L. 135

$\left\lceil\begin{array}{r}\text { Pressure } \\ \text { orifices }\end{array}\right.$

B.L. 325

B.L. 350

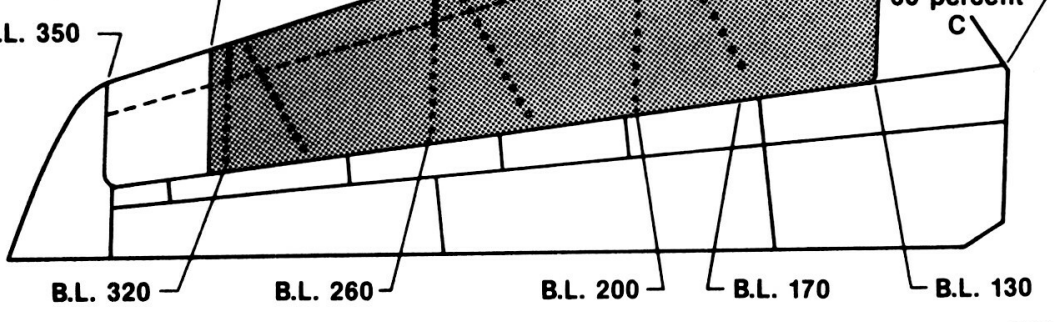

8435

Fig. 3 Glove 1 planform and instrumentation.

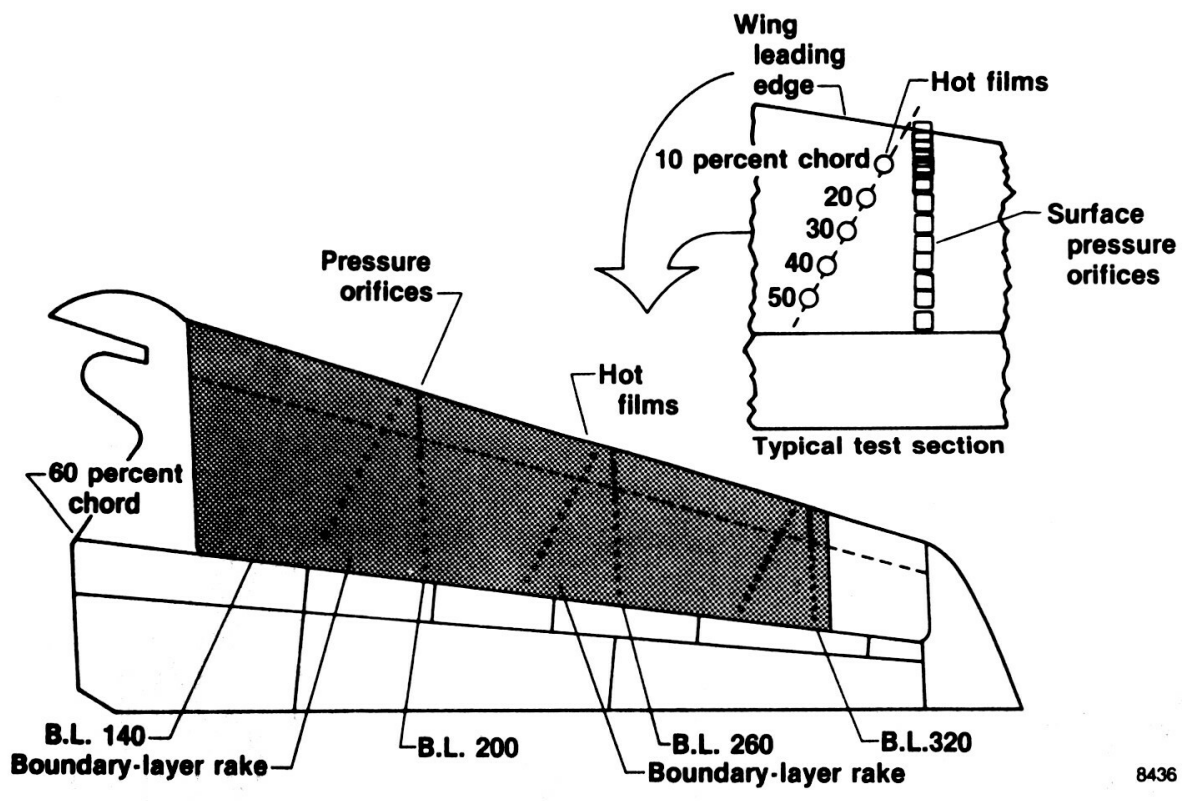

Fig. 4 Glove 2 planform and instrumentation. 
On MHE FEन W

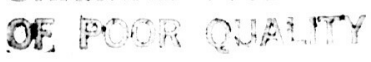

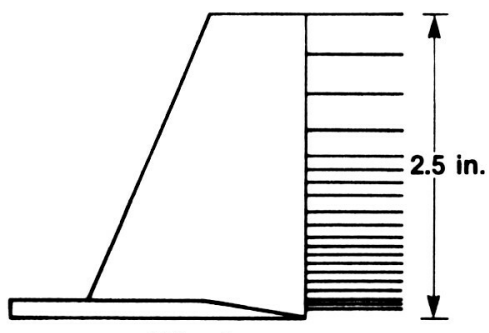

Side view

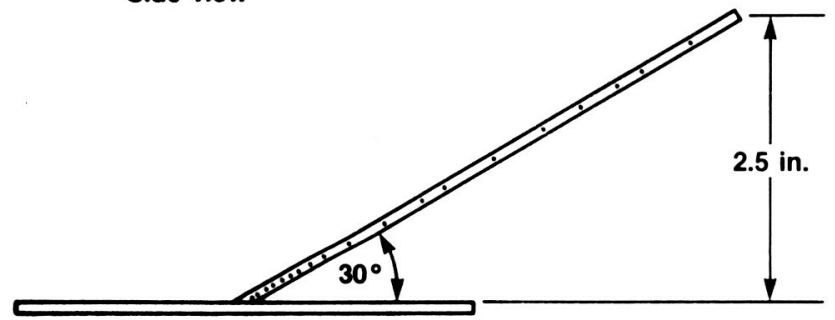

Front view

Fig. 5 diagram of boundary-layer rake.
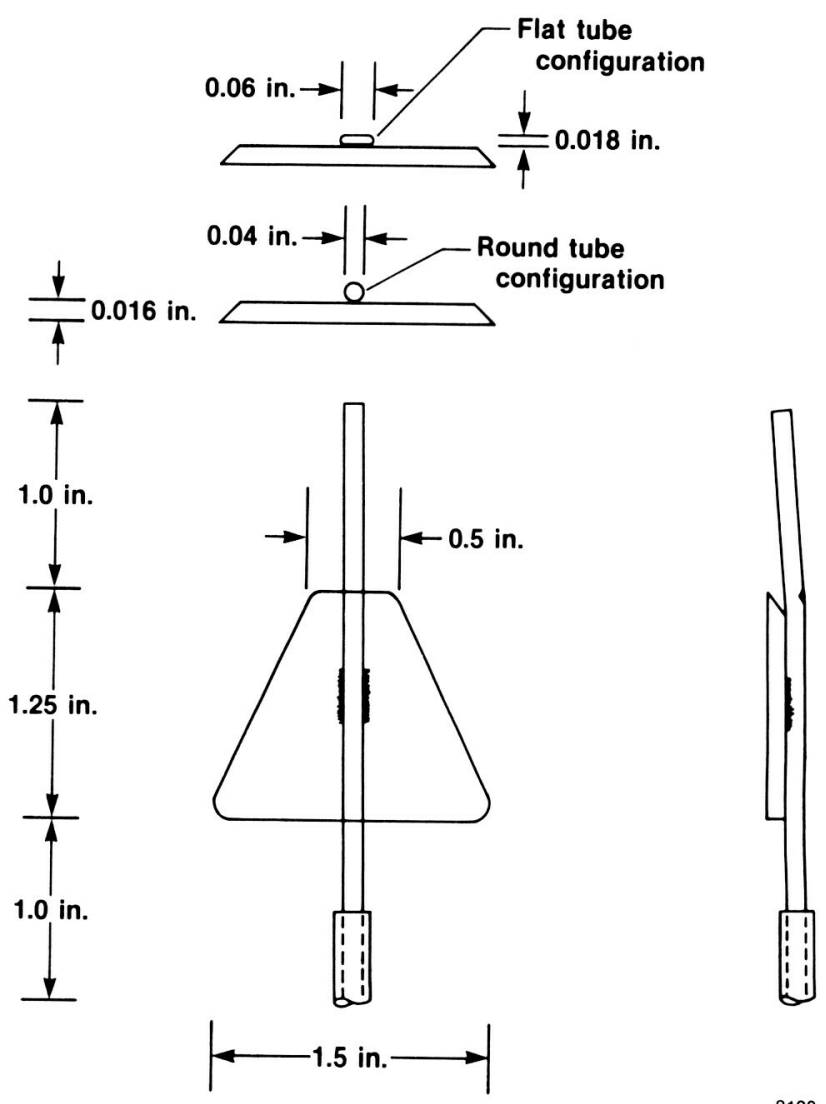

Fig. 6 Schematic of surface pitot tube.

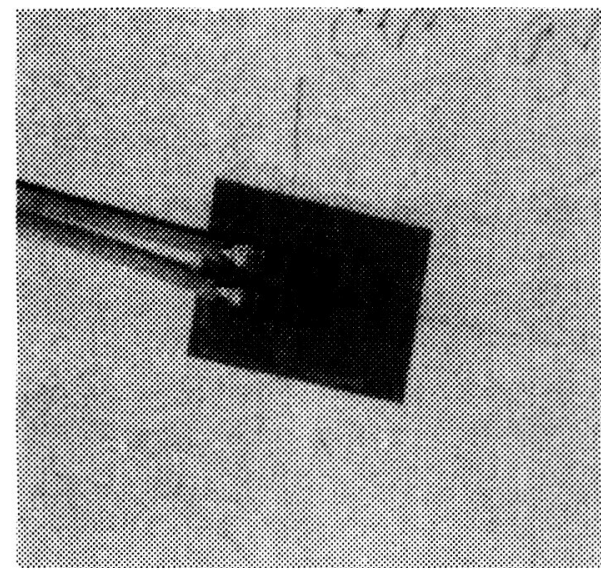

EC 86-33426-009

(a) Sensor used on glove 1 .

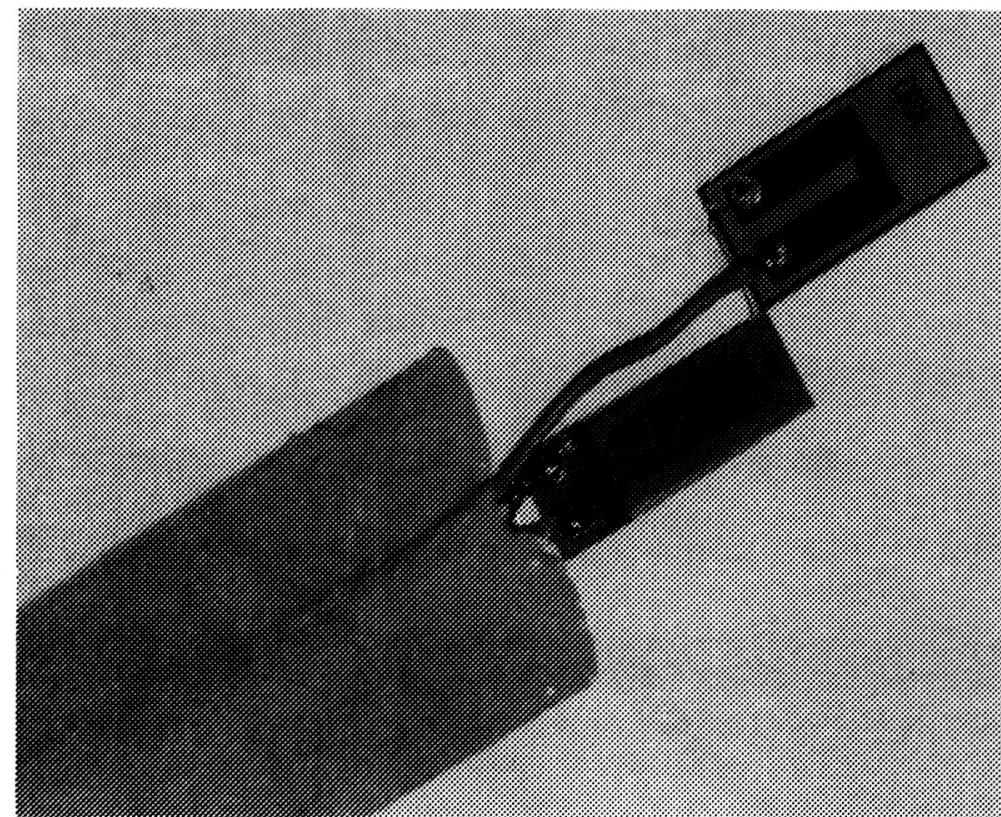

EC 86-33329-002

(b) Sensors used on glove 2.

Fig. 7 Hot-film sensors. 


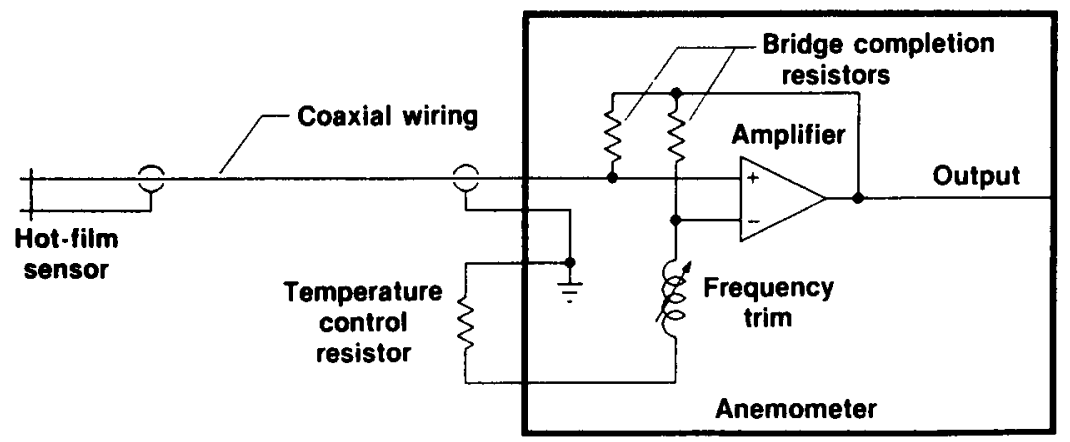

(a) Constant temperature.

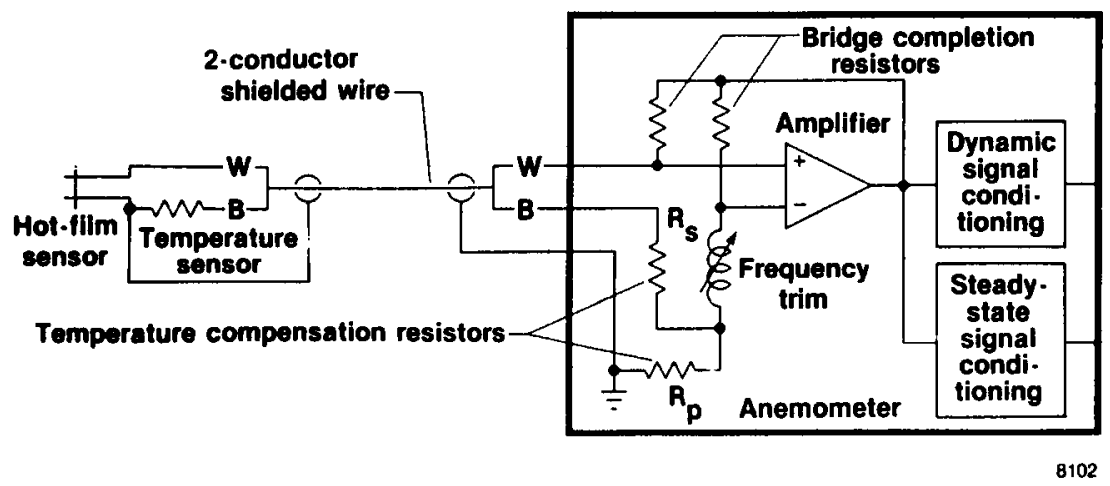

(b) Temperature compensated.

Fig. 8 Functional block diagrams of hot-film anemometers.

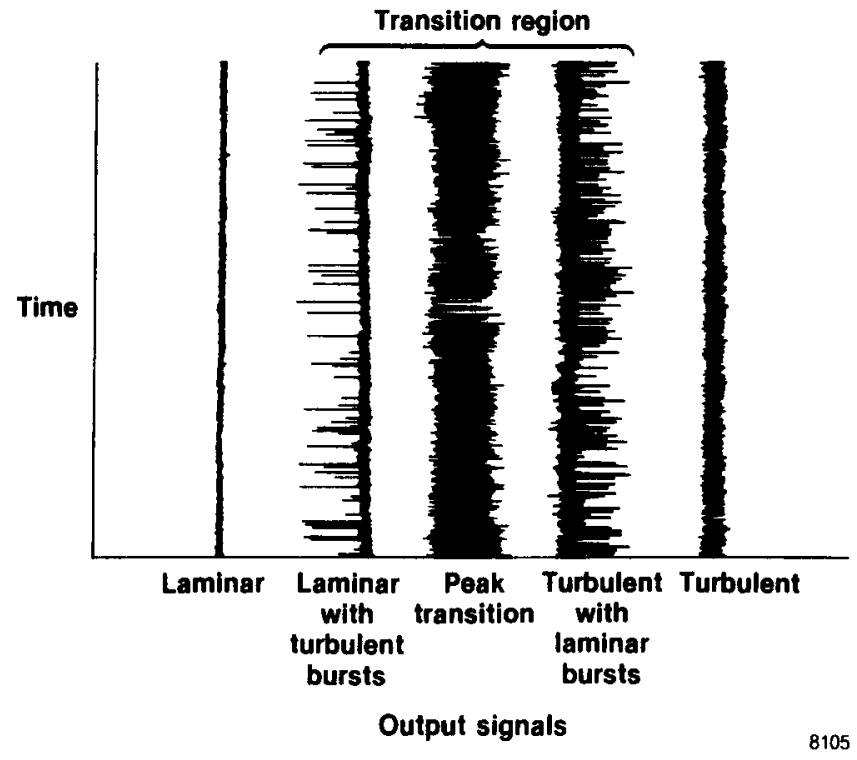

(a) Dynamic, AC, hot-film output signals.

Fig. 9 Typical hot-film output signals. 


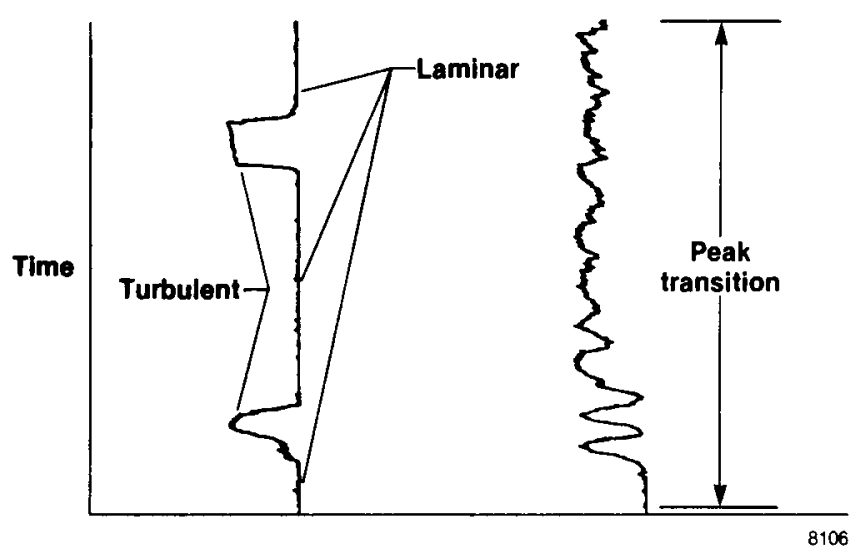

(b) Steady-state output signal.

Fig. 9 Concluded.

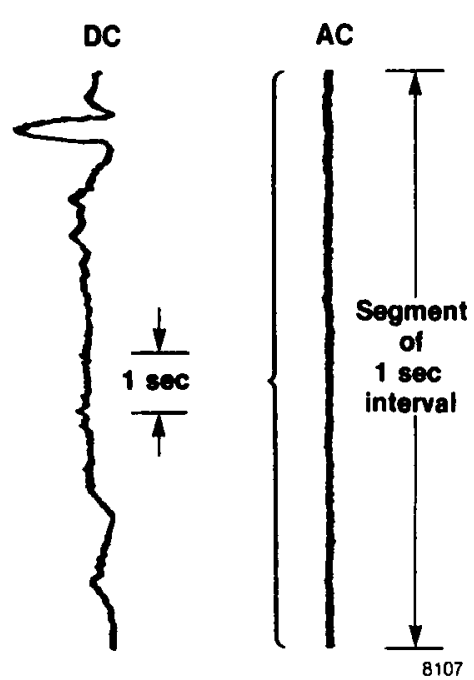

(a) Laminar DC and $A C$ signals.

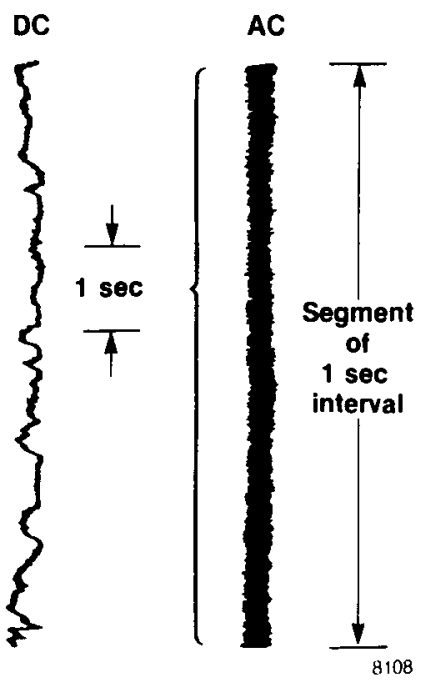

(b) Laminar DC signal and turbulent AC signal.

Fig. 10 Hot-film signal comparisons. 


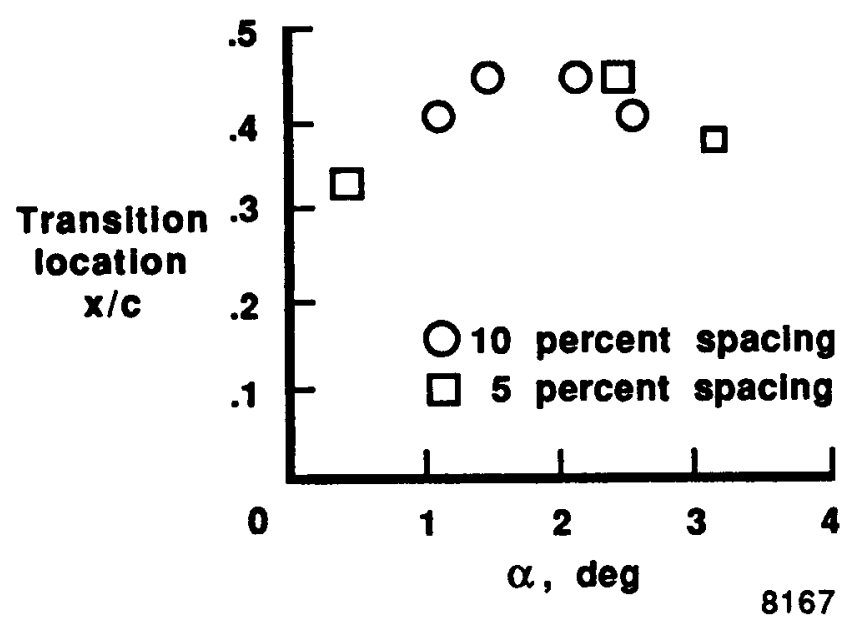

Fig. 11 Comparison of hot-film data with chordwise spacings of 10 percent and 15 percent.

O Natural transition

$\square \mathbf{1 0}$ percent forced 030 percent forced

$\triangle 40$ percent forced

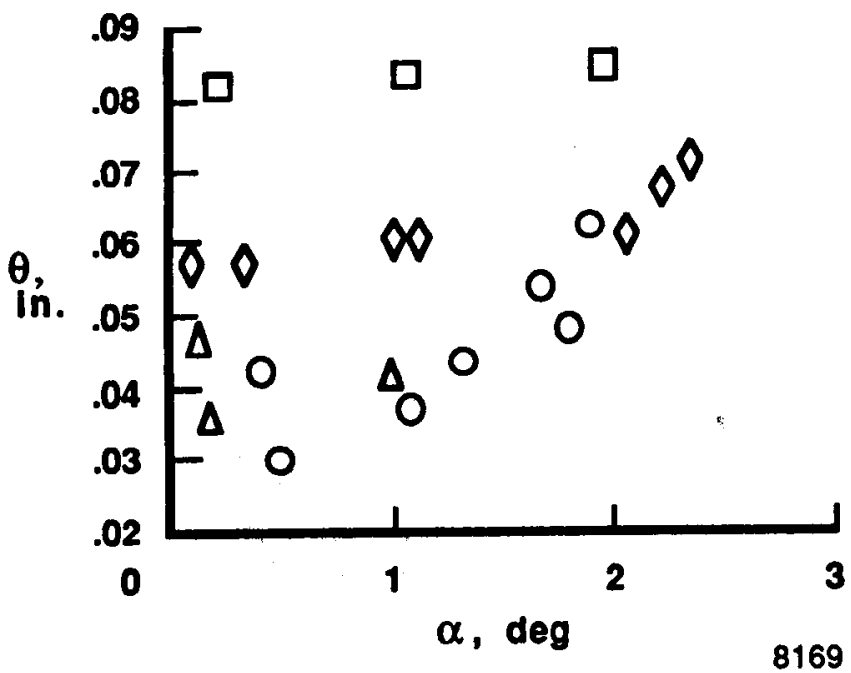

Fig. 13 Boundary-layer rake transition data.

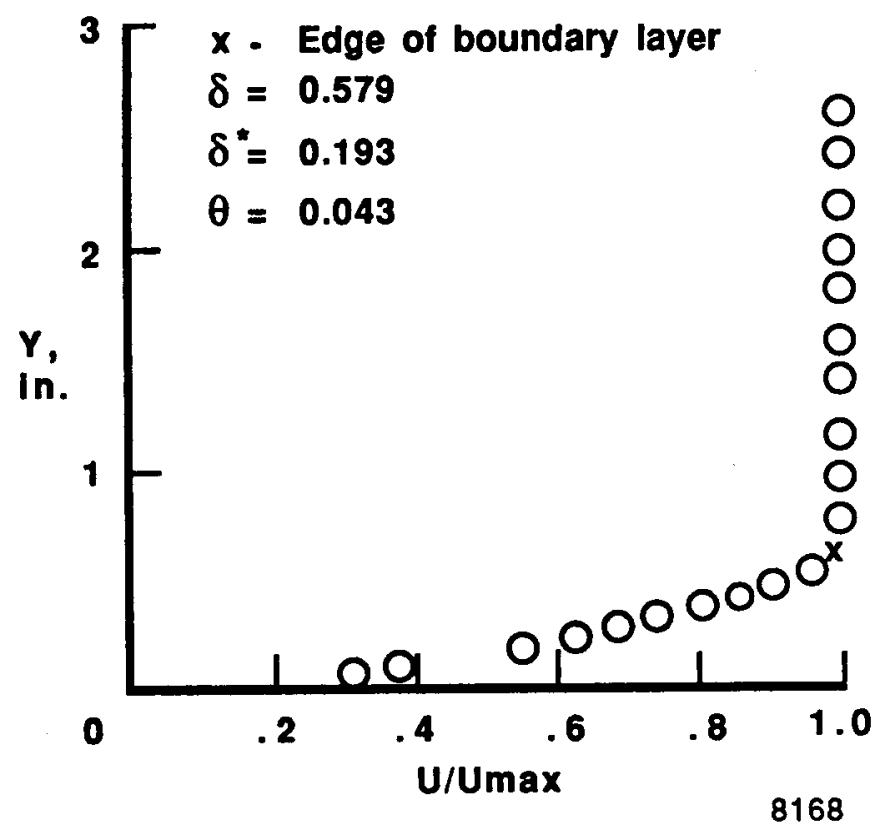

Fig. 12 Typical boundary-layer profile.

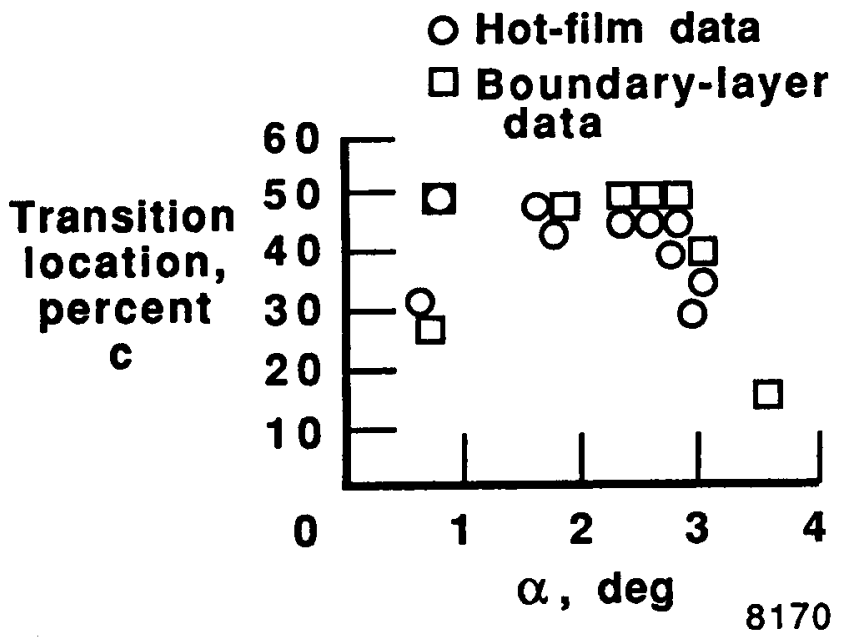

Fig. 14 Comparison of hot-film and boundary-layer data. 


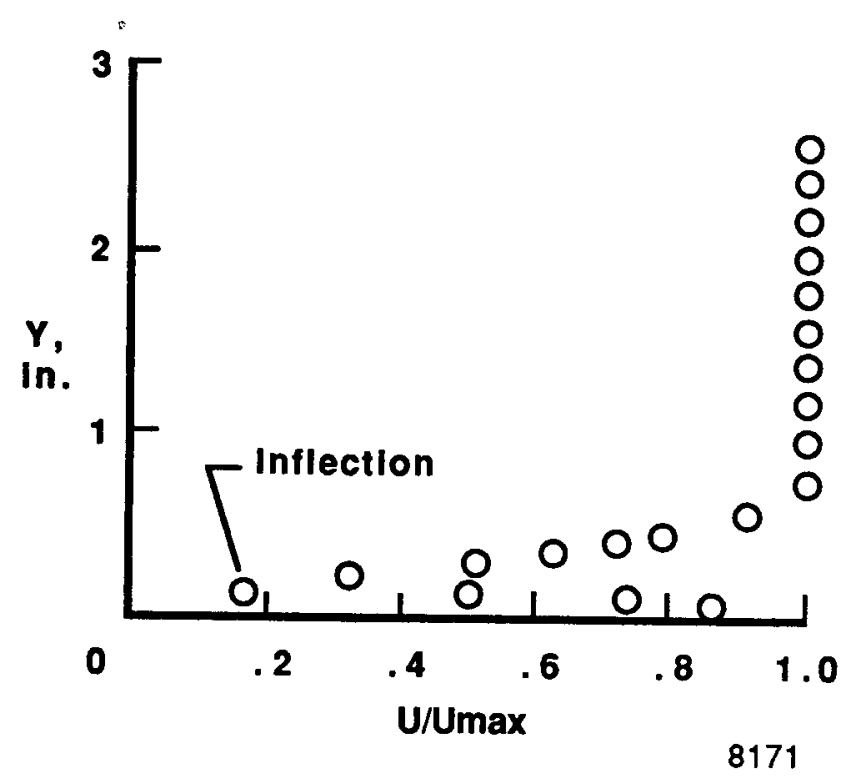

(a)

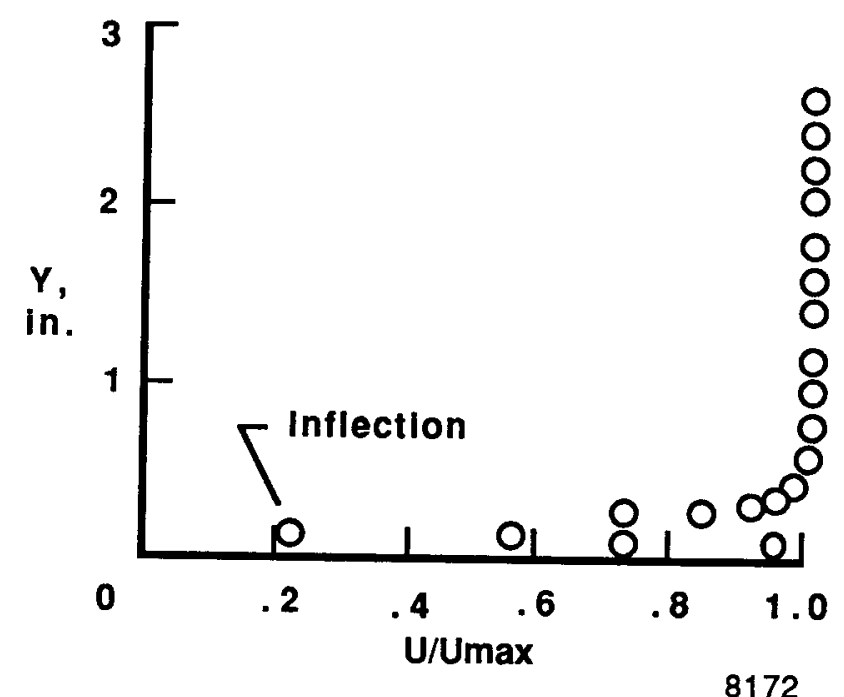

(b)

Fig. 15 Examples of boundary-layer profiles with inflections.

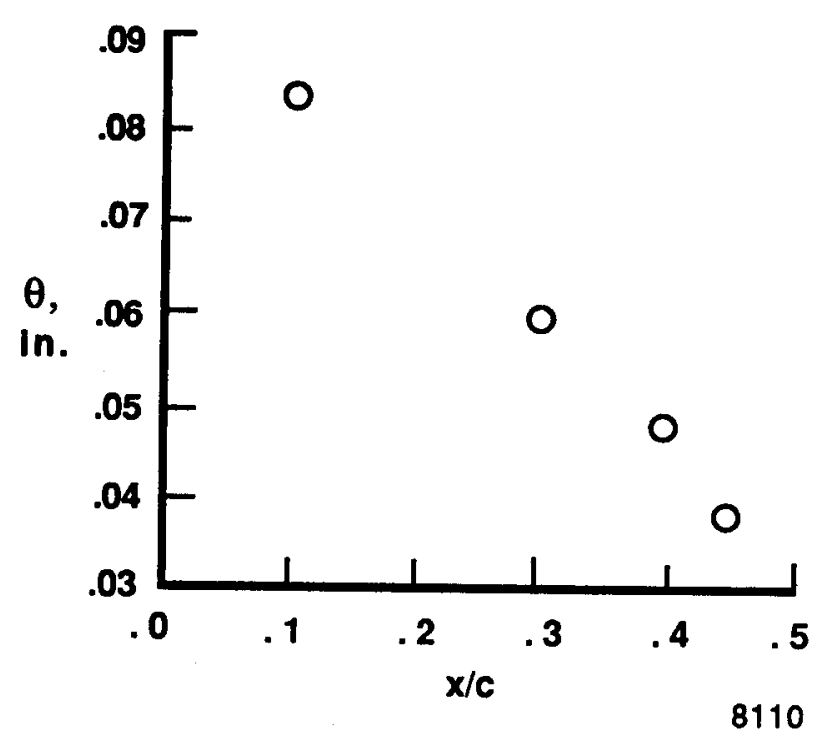

Fig. 16 Momentum thickness as a function of transiticn location.

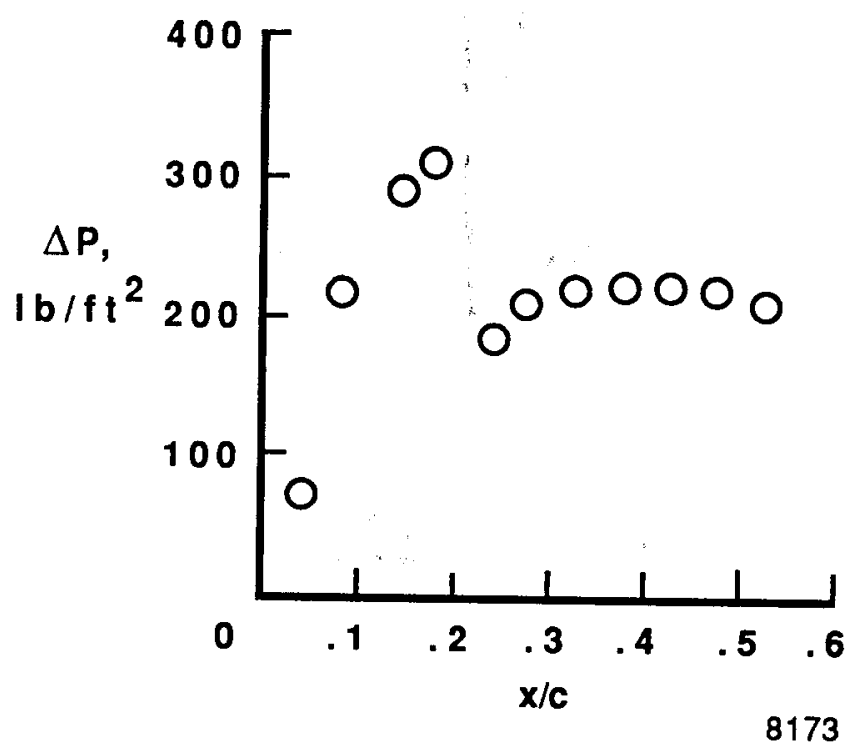

Fig. 17 Typical surface pitot tube data. 


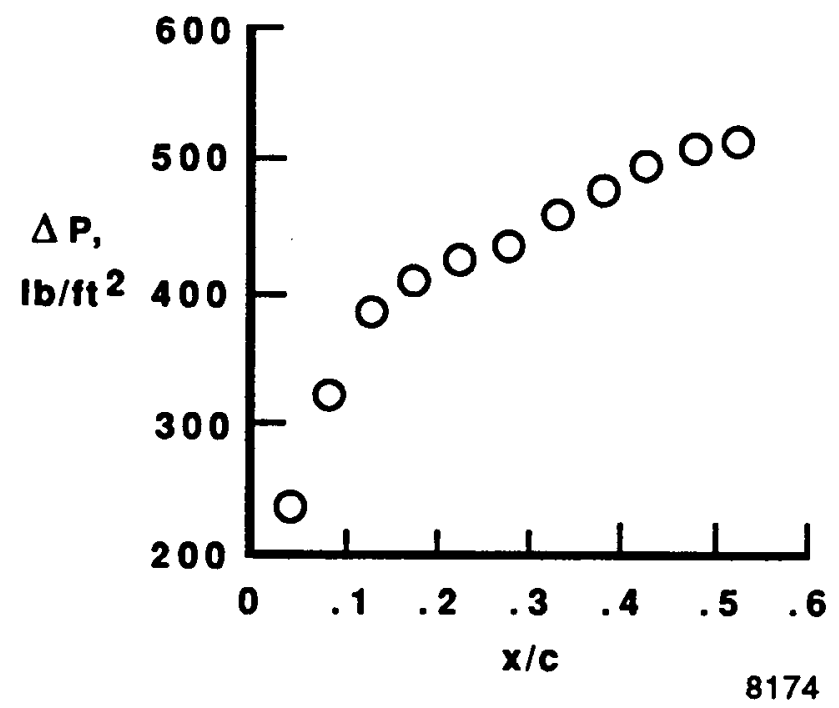

Fig. 18 Laminar or fully turbulent surface pitot tube data.

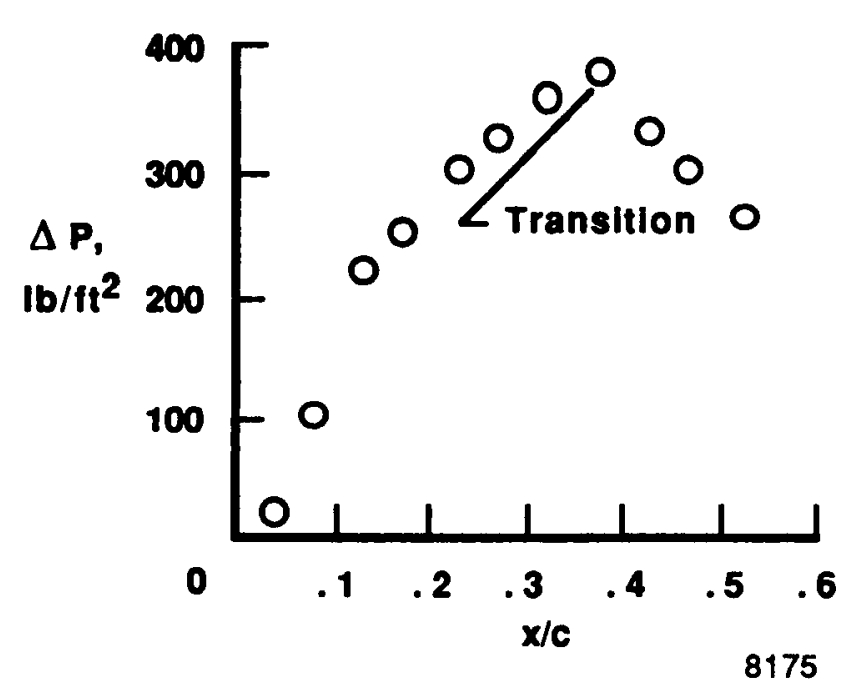

(a)

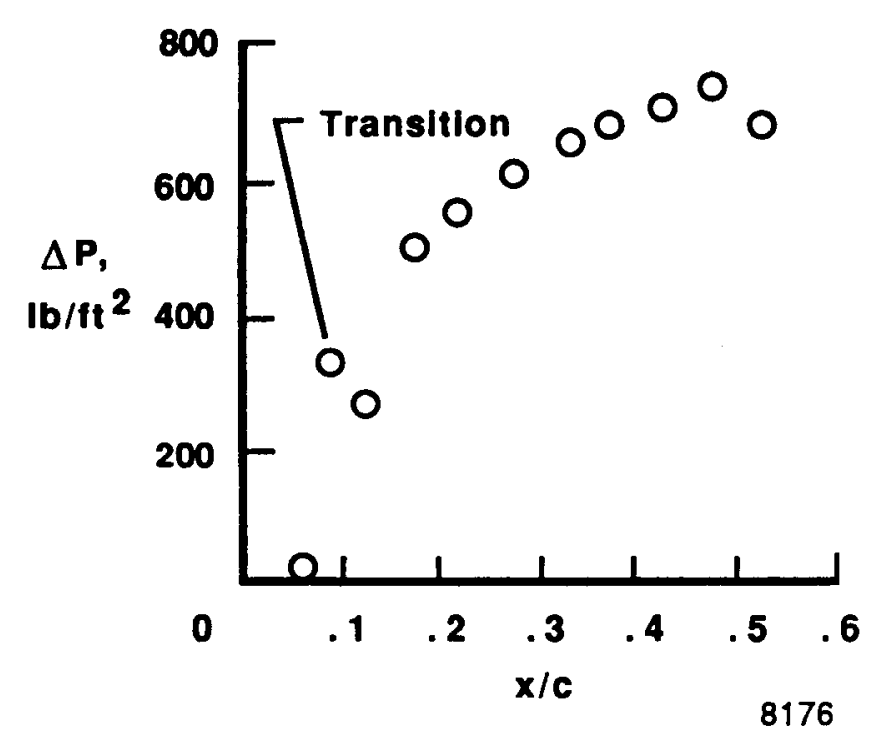

(b)

Fig. 19 Typical surface pitot tube transition data. 


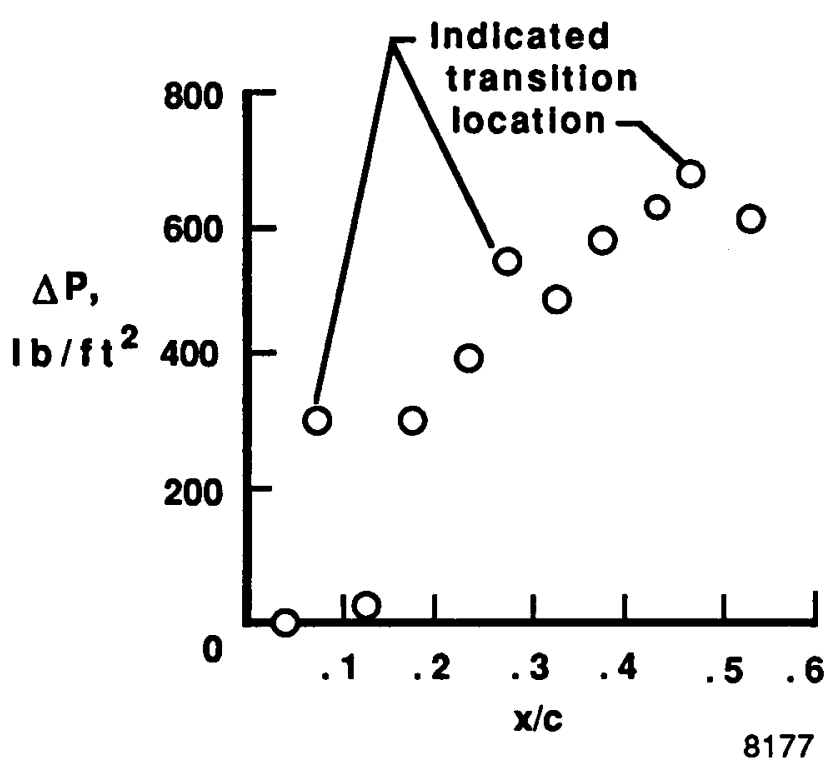

(a)

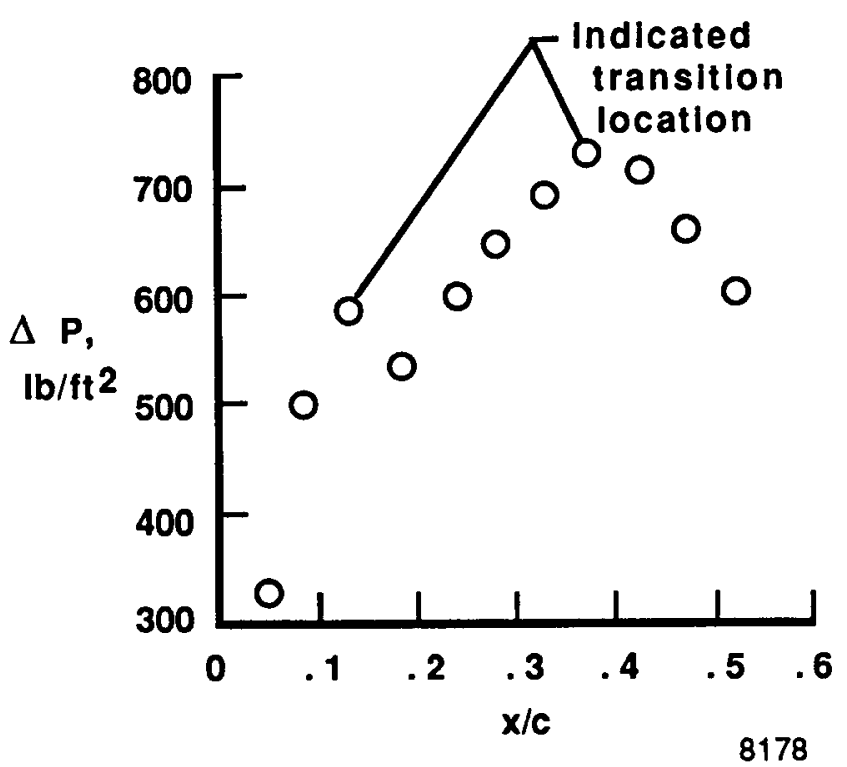

(b)

Fig. 20 Surface pitot tube data indicating more than one transition location.

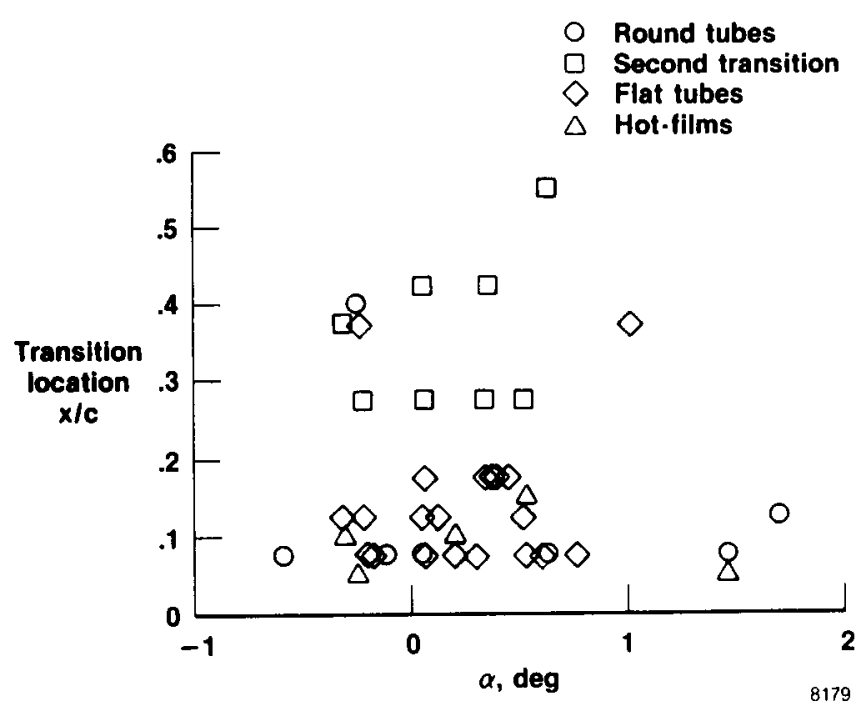

(a) Low-altitude data.

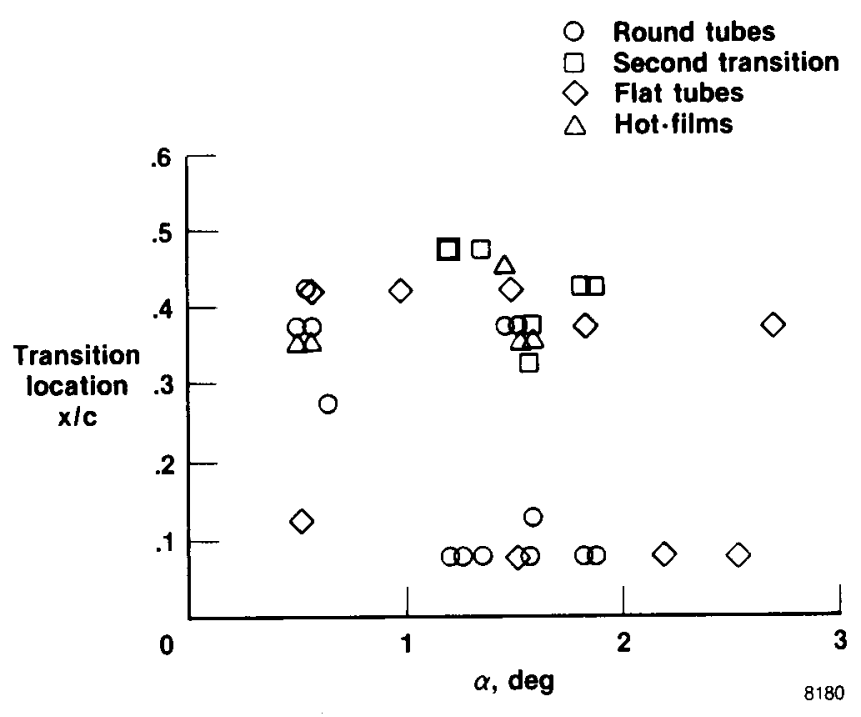

(b) High-altitude data.

Fig. 21 Comparison of hot-film and surface pitot tube data. 
ORIGINAL PAGE IS

OF POOR QUALTTY



(a)

EC 86-33600-016

Fig. 22 Examples of liquid crystal patterns. 


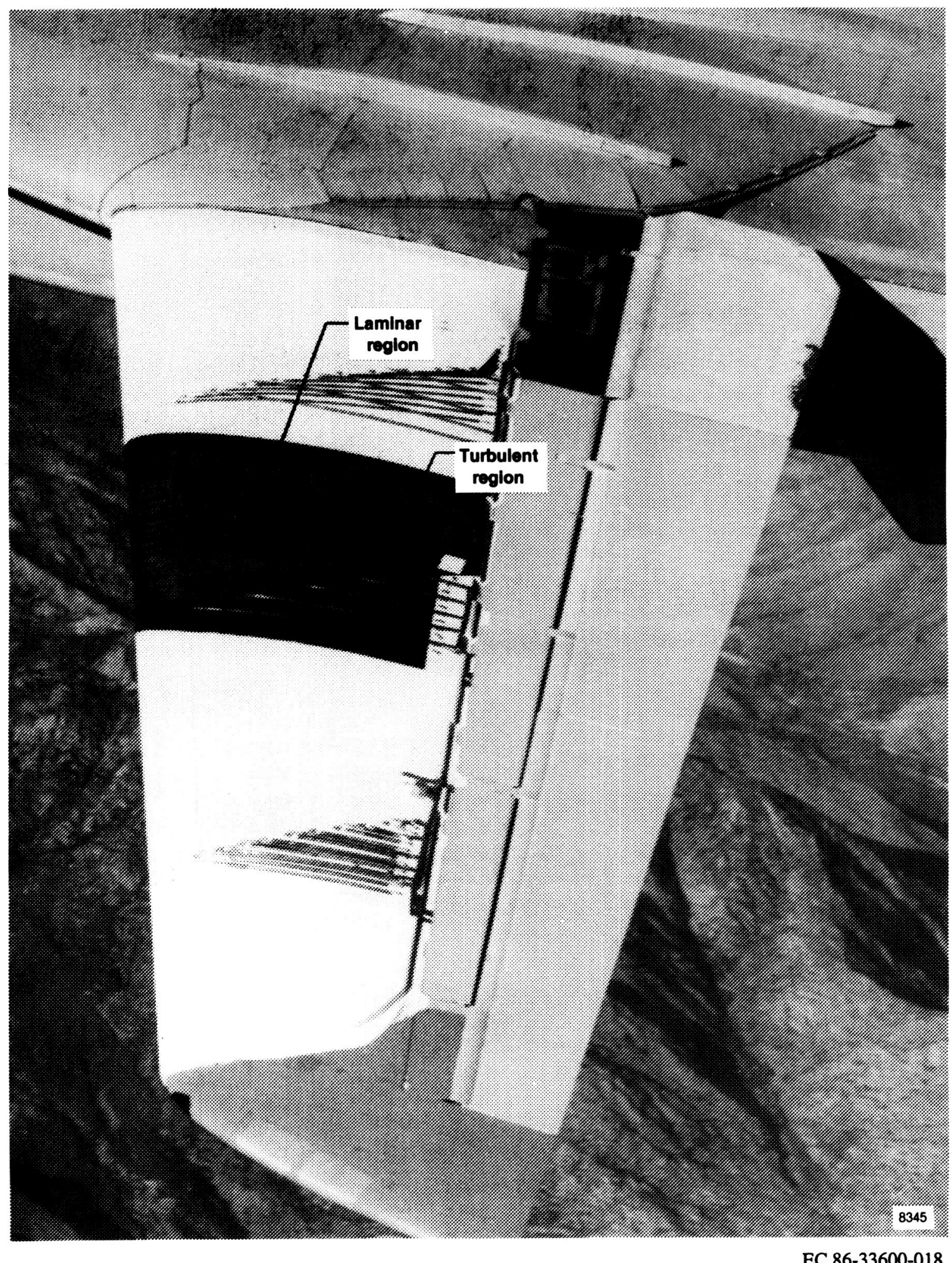

(b)

Fig. 22 Concluded. 


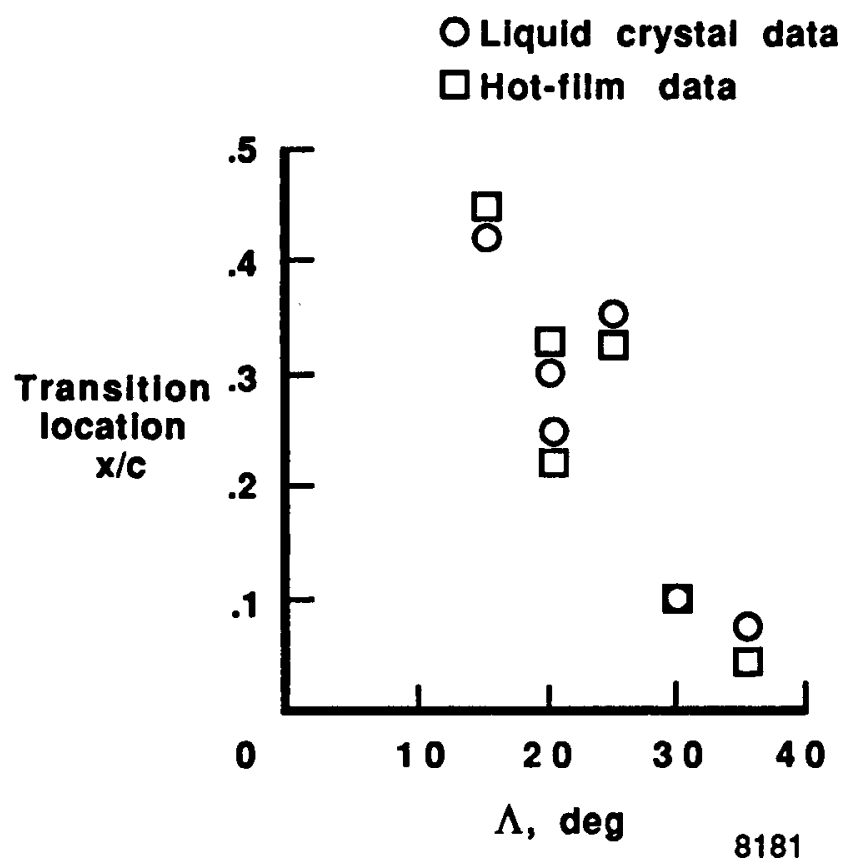

(a) Glove 1 data.

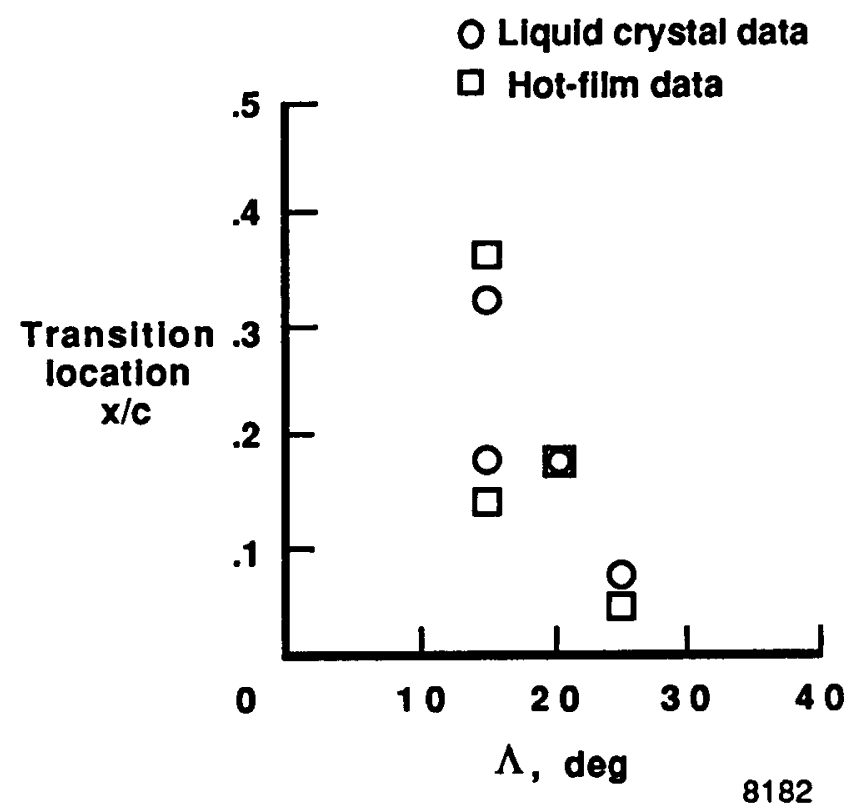

(b) Glove 2 data.

Fig. 23 Comparison of hot-film and liquid crystal data.

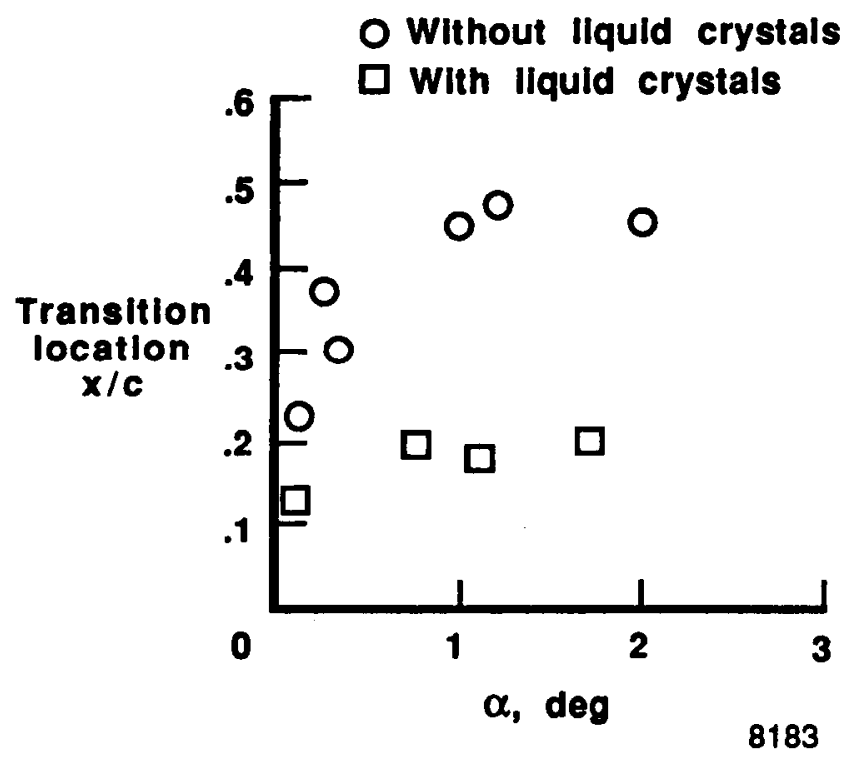

(a) Low-altitude data.

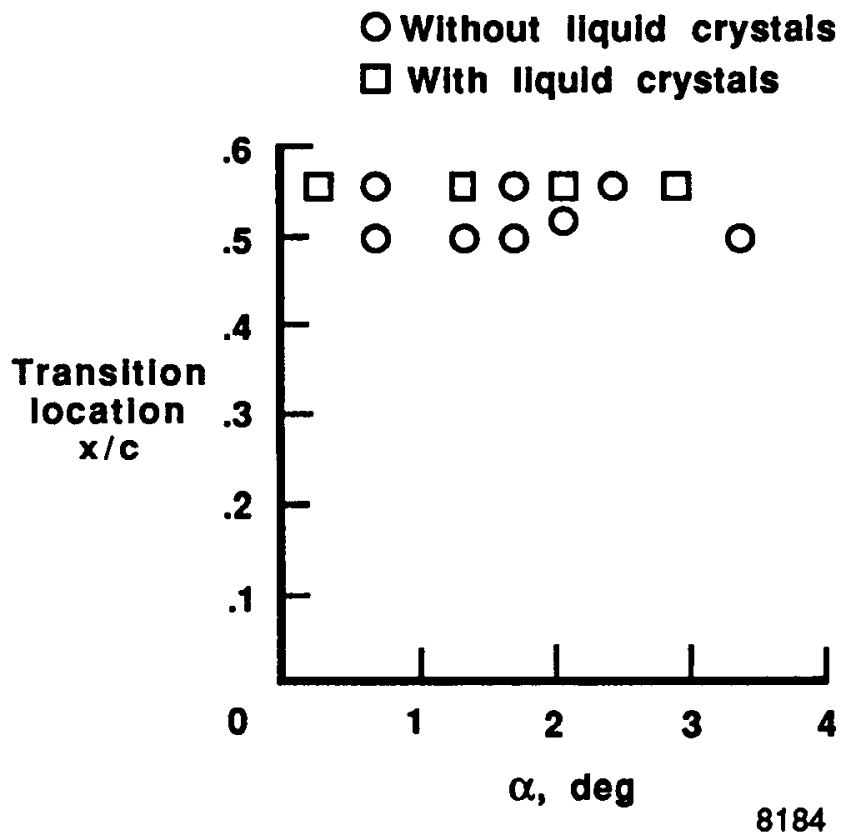

(b) High-altitude data.

Fig. 24 Comparison of transition data with and without liquid crystals on the glove surface. 


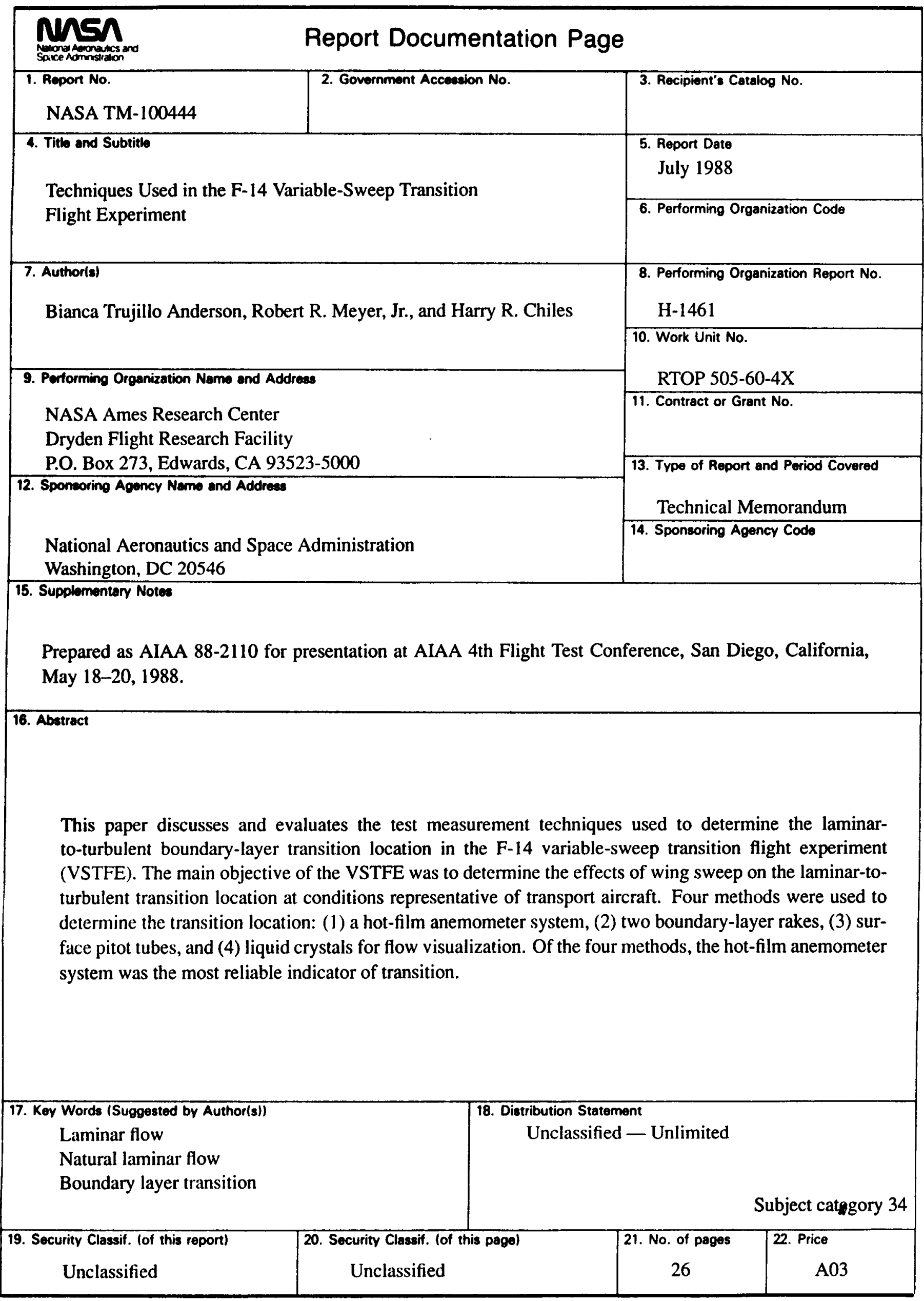

